\title{
KTD1 is a yeast defense factor against K28 killer toxin
}

\section{Ilya Andreev ${ }^{1, \dagger}$, Simone M. Giovanetti ${ }^{1}$, Guillaume Urtecho ${ }^{2, \uparrow}$, Daniel Shriner ${ }^{3}$, Joshua S. Bloom $^{4,5,6,7,8}$, Meru J. Sadhu ${ }^{1, *}$}

${ }^{1}$ Genetic Disease Research Branch, National Human Genome Research Institute, National Institutes of Health, Bethesda, MD 20892, USA.

${ }^{2}$ Molecular Biology Interdepartmental Doctoral Program, University of California, Los Angeles, Los Angeles, CA 90095, USA.

${ }^{3}$ Center for Research on Genomics and Global Health, National Human Genome Research Institute, National Institutes of Health, Bethesda, MD 20892, USA.

${ }^{4}$ Department of Human Genetics, University of California, Los Angeles, Los Angeles, CA 90095, USA.

${ }^{5}$ Department of Biological Chemistry, University of California, Los Angeles, Los Angeles, CA 90095, USA.

${ }^{6}$ Howard Hughes Medical Institute, University of California, Los Angeles, Los Angeles, CA 90095, USA.

${ }^{7}$ Institute for Quantitative and Computational Biology, University of California, Los Angeles, Los Angeles, CA 90095, USA.

${ }^{8}$ Department of Computational Medicine, University of California, Los Angeles, Los Angeles, CA, 90095, USA.

*Corresponding author. Email: meru.sadhu@nih.gov (M.J.S.)

$\dagger$ Current address: Department of Biology, Massachusetts Institute of Technology, Cambridge, MA 02139, USA.

\$ Current address: Department of Systems Biology, Columbia University, New York, NY 10032, USA.

\begin{abstract}
Secreted protein toxins are widely used weapons in conflicts between organisms. Killer yeast produce killer toxins that inhibit the growth of nearby sensitive yeast. We investigated variation in resistance to the killer toxin K28 across diverse natural isolates of the Saccharomyces cerevisiae population and discovered a novel defense factor, which we named KTD1, that is an important determinant of K28 toxin resistance. KTD1 is a member of the DUP240 gene family of unknown function. We uncovered a putative role of DUP240 proteins in killer toxin defense and identified a region that is undergoing rapid evolution and is critical to KTDl's protective ability. Our findings implicate $K T D 1$ as a key factor in the defense against killer toxin K28.
\end{abstract}




\section{Introduction}

Conflict between organisms is a major evolutionary force, both within and between species, and can lead to complex molecular arms races of competing evolutionary adaptation. Secreted protein toxins are a common weapon in biological conflict, encountered across all domains of life (1-3). Exposure to these toxins can select for adaptations in targeted organisms that allow them to resist toxic effects $(4-11)$.

Toxin-secreting killer yeast strains of Saccharomyces cerevisiae are a well-studied example of conflict in the microbial world (12). They are infected by dsRNA killer viruses, which encode killer toxins that the killer yeast secrete to inhibit the growth of nearby susceptible yeast strains. As killer viruses also protect their hosts from the secreted toxins, a killer virus infection is beneficial to the host in competition with sensitive cells (13-15). The killer toxin K28, encoded by the M28 killer virus, enters target cells by hijacking their retrograde trafficking pathway, ultimately translocating to the cytoplasm and inducing G1/S cell cycle arrest through an unknown mechanism (16). The biology of K28 toxicity has been extensively studied; however, it is unknown whether natural populations of $S$. cerevisiae have adapted strategies of resistance to this killer toxin, if at all. Here, we leveraged natural variation in yeast to investigate whether cells have evolved mechanisms of protection against K28.

\section{Results}

We surveyed K28 killer toxin resistance in a diverse panel of $16 S$. cerevisiae strains isolated from a variety of geographical locations and ecological settings (17) (Fig. 1A; table S1) and found that they ranged from completely resistant to highly sensitive to K28 (Fig. 1B, fig. S1), consistent with past reports of variation in killer toxin resistance (18-20). Yeast infected with M28 killer virus are resistant to K28, as killer viruses confer toxin self-immunity upon the host cell (21). However, we did not detect M28 killer virus in any of these strains (figs. S2, S3), in keeping with previous findings that most yeast isolates are not infected by killer viruses (19, 20, $22,23)$. This suggests that differences in toxin resistance are due to variation in chromosomally encoded genetic factors. 
To identify genes controlling variation in toxin resistance, we initially focused on the K28resistant lab isolate BY and the highly sensitive wine isolate RM (table S1). We determined the toxin resistance of 912 fully genotyped haploid segregants generated from a BY $\times$ RM cross (24) by comparing growth in media with or without K28 toxin (Fig. 2A). Linkage analysis revealed three quantitative trait loci (QTLs) associated with K28 resistance (Fig. 2B, table S2). The strongest QTL was on chromosome I: only $2 \%$ of segregants with the RM allele grew robustly in the presence of K28, as opposed to $40 \%$ of the segregants with the BY allele (Fig. 2C). The 95\% confidence interval for this QTL was $4.0 \mathrm{~kb}$, with the peak located between the genes UIP3 and YAR028W. Both genes are members of the DUP240 gene family of unknown function $(25,26)$.

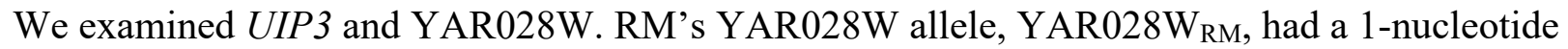
frameshift mutation at codon 136 (Fig. 2B, inset), leading to 13 additional out-of-frame codons and a premature stop; in comparison, BY's intact allele is 235 codons long. In contrast, both strains had full-length UIP3 alleles. Analysis of ribosome footprinting data collected by Albert, et al. (27) showed that YAR028W is expressed and translated in BY, but its translation ends prematurely in RM, near the frameshift mutation (fig. S4). Furthermore, a genome-wide screen of 4806 deletion mutants in the yeast knockout collection, which is isogenic to BY, annotated the YAR028W deletion mutant, yar028w4, as partially sensitive to K28 (28). We confirmed that yar028w4 is sensitive to K28, whereas we observed no effect of deleting UIP3 (Fig. 2D and figs. S5, S6). Importantly, plasmid-based expression of the BY allele of YAR028W, YAR028W $\mathrm{BY}_{\mathrm{BY}}$, in the sensitive RM and yar028wA strains provided strong protection against K28 (Fig. 2, D and E, fig. S6), while the RM allele had no effect (fig. S6). We concluded that YAR028W underlies the dramatic difference in K28 resistance between BY and RM. Therefore, we designated YAR028W as KTD1 ( $k$ iller toxin defense).

We examined the molecular defense mechanism of Ktd1p. The first step in the process of K28 cytotoxicity is K28 binding to the cell wall (16), so we tested whether Ktd1p counters K28 at this step or after. Using a toxin adsorption assay $(28,29)$, we assayed the ability of K28 to bind to the surface of strains with or without $K T D 1_{\mathrm{BY}}$ and in different genetic backgrounds. We found that expression of $K T D 1_{\mathrm{BY}}$ did not reduce $\mathrm{K} 28$ binding (fig. S7). Additionally, toxin-sensitive RM did not exhibit higher K28 binding than toxin-resistant BY. As a control, we recapitulated that deletion of the mannosyltransferase MNN2 prevents K28 binding (28). We therefore concluded that $K T D 1$ functions after the initial step of toxin binding to the cell surface. 
We next explored the connection between variation in KTD1 and K28 resistance across the yeast population. We found that $37 \%$ of 1,011 S. cerevisiae strains sequenced in a recent population survey had a premature stop mutation at codon 141 (30) (Fig. 3A). This polymorphism is also present in $K T D 1_{\mathrm{RM}}$ (Fig. 2B, inset, black dashed box), indicating it was already truncated prior to acquiring the frameshift mutation. Examining the strains in our panel, the strain YJM981 carried the ktd1-141Stop mutation without the frameshift (fig. S8) and was also highly sensitive to K28. Two other sensitive strains in our panel, YPS1009 and I14, had full-length KTD1 alleles, albeit with multiple nonsynonymous mutations in each (fig. S8). We tested whether any of these KTD1 alleles conferred toxin resistance upon the sensitive $k t d 1 \Delta$ strain. Expression of KTD $1_{\text {YJM981 }}$ or KTD1 $1_{\text {YPS1009 }}$ did not protect against K28 toxin (Fig. 3B). However, KTD1 114 did confer K28 resistance, indicating that strain I14's toxin sensitivity is caused by a different mechanism despite carrying a protective KTD1 allele. We tested three additional KTD1 alleles shared between five K28-resistant strains and found that all of them restored toxin resistance in the $k t d 1 \Delta$ strain (Fig. 3B). Our results indicate that KTDl function is a major determinant of variation in $\mathrm{K} 28$ resistance across the yeast population.

KTD1 is a member of the enigmatic DUP240 gene family. None of the 10 DUP240 genes in the reference genome have a clearly ascribed function (table S3), and simultaneous deletion of all DUP240 genes does not affect yeast growth (25). Moreover, this family recently arose in the Saccharomycetaceae family (fig. S9), and the number and composition of this family varies widely between strains (26) (table S4). DUP240 proteins have two predicted transmembrane domains separated by a short inter-helix linker. To identify the protein domains responsible for protection, we constructed chimeras between Ktd1p and Uip3p (Fig. 4A), the latter of which is the closest DUP240 family member with $58.1 \%$ amino acid identity to Ktd1p (fig. S10) but does not confer K28 resistance. Our experiments identified two regions of Ktd1p important for protection: the inter-helix linker and the C-terminus (Fig. 4A). When Ktd1p's 88 C-terminal amino acids were replaced with the corresponding region of Uip3p (chimera K/U-2), K28 resistance was fully abrogated. In addition, chimeras U/K-5 and U/K-6, which differed only in the identity of their inter-helix linker, showed very different K28 protection responses (Fig. 4A), indicating a key role for Ktd1p's inter-helix linker in K28 protection. The inter-helix linker region was of particular interest, as it is predicted to reside on the non-cytoplasmic face of the 
membrane (31) and thus is the only part of Ktd1p that could reside in the same cellular compartment as K28 before it reaches the cytoplasm (16).

We noted that the linker and its surrounding sequence are highly diverged between DUP240 family members (fig. S11). Proteins involved in host defense often experience evolutionary pressure to change (32), which at the genetic level can manifest as a higher nonsynonymous mutation rate relative to synonymous mutation rate $(\mathrm{dN} / \mathrm{dS})$. We searched the genomes of our 16-isolate yeast panel for ORFs encoding proteins homologous to known DUP240s and selected 18 orthologs to generate models of $\mathrm{dN} / \mathrm{dS}$ ratios per codon using the codeml package in PAML (33). Ten codons were identified as having $\mathrm{dN} / \mathrm{dS}>1$, indicating positive selection at those sites (table S5). The corresponding residues are concentrated in the region spanning the transmembrane helices and the linker (Fig. 4B, fig. S11). Combined, the evidence of positive selection in the Ktd1p inter-helix linker and its role in K28 protection suggest that the DUP240 family evolved under selective pressure from killer toxins.

\section{Discussion}

Protein toxins are powerful weapons in inter- and intra-species competition that can lead to polymorphic adaptations in the targeted populations $(4-7,10,34)$. We discovered a polymorphic yeast gene, KTD1, that protects yeast against the killer toxin K28. KTD1 is a member of the enigmatic DUP240 gene family, a rapidly expanding and contracting family of genes with unknown function. We found many distinct alleles of KTD1 in the yeast population, including a highly prevalent premature stop codon, which could reflect coevolution with K28, varying across the diverse environments and geographical locations in which yeast are found. KTD1 is under positive selection at the molecular level, concentrated in amino acids in the transmembrane domains and the linker between them, which is critical for Ktd1p-mediated resistance to K28. After binding to the cell surface, K28 is endocytosed and then avoids vacuolar degradation (16), instead travelling to the ER before entering the cytoplasm. Ktd1p might provide resistance by facilitating vacuolar degradation of K28, consistent with our finding that Ktd1p acts after K28 binds to the cell surface and the involvement of other DUP240s in protein trafficking (35) and the related DUP380s in mediating degradation of endocytosed proteins (36). 


\section{References}

1. L. Dang, E. J. M. Van Damme, Toxic proteins in plants. Phytochemistry. 117 (2015), pp. $51-64$.

2. J. Alouf, D. Ladant, M. R. Popoff, The Comprehensive Sourcebook of Bacterial Protein Toxins (Elsevier Inc., ed. 4, 2015).

3. N. Chen, S. Xu, Y. Zhang, F. Wang, Animal protein toxins: origins and therapeutic applications. Biophys. Reports. 4, 233-242 (2018).

4. S. L. Geffeney, E. Fujimoto, E. D. Brodie, E. D. Brodie, P. C. Ruben, Evolutionary diversification of TTX-resistant sodium channels in a predator-prey interaction. Nature. 434, 759-763 (2005).

5. V. M. Bricelj, L. Connell, K. Konoki, S. P. MacQuarrie, T. Scheuer, W. A. Catterall, V. L. Trainer, Sodium channel mutation leading to saxitoxin resistance in clams increases risk of PSP. Nature. 434, 763-767 (2005).

6. E. D. Boyden, W. F. Dietrich, Nalp1b controls mouse macrophage susceptibility to anthrax lethal toxin. Nat. Genet. 38, 240-244 (2006).

7. E. K. Karlsson, J. B. Harris, S. Tabrizi, A. Rahman, I. Shlyakhter, N. Patterson, C. O’Dushlaine, S. F. Schaffner, S. Gupta, F. Chowdhury, A. Sheikh, O. S. Shin, C. Ellis, C. E. Becker, L. M. Stuart, S. B. Calderwood, E. T. Ryan, F. Qadri, P. C. Sabeti, R. C. LaRocque, Natural selection in a bangladeshi population from the cholera-endemic ganges river delta. Sci. Transl. Med. 5 (2013), doi:10.1126/scitranslmed.3006338.

8. C. M. Carey, S. E. Apple, Z. A. Hilbert, M. S. Kay, N. C. Elde, Diarrheal pathogens trigger rapid evolution of the guanylate cyclase-C signaling axis in bats. Cell Host Microbe (2021), doi:10.1016/j.chom.2021.07.005.

9. H. Xu, J. Yang, W. Gao, L. Li, P. Li, L. Zhang, Y. N. Gong, X. Peng, J. J. Xi, S. Chen, F. Wang, F. Shao, Innate immune sensing of bacterial modifications of Rho GTPases by the Pyrin inflammasome. Nature. 513, 237-241 (2014).

10. Y. H. Park, E. F. Remmers, W. Lee, A. K. Ombrello, L. K. Chung, Z. Shilei, D. L. Stone, M. I. Ivanov, N. A. Loeven, K. S. Barron, P. Hoffmann, M. Nehrebecky, Y. Z. AkkayaUlum, E. Sag, B. Balci-Peynircioglu, I. Aksentijevich, A. Gül, C. N. Rotimi, H. Chen, J. B. Bliska, S. Ozen, D. L. Kastner, D. Shriner, J. J. Chae, Ancient familial Mediterranean fever mutations in human pyrin and resistance to Yersinia pestis. Nat. Immunol. 21, 857867 (2020).

11. T. Krassowski, A. Y. Coughlan, X. X. Shen, X. Zhou, J. Kominek, D. A. Opulente, R. Riley, I. V. Grigoriev, N. Maheshwari, D. C. Shields, C. P. Kurtzman, C. T. Hittinger, A. Rokas, K. H. Wolfe, Evolutionary instability of CUG-Leu in the genetic code of budding yeasts. Nat. Commun. 9, 1-8 (2018).

12. M. J. Schmitt, F. Breinig, Yeast viral killer toxins: lethality and self-protection. Nat Rev Micro. 4, 212-221 (2006).

13. M. D. Pieczynska, D. Wloch-Salamon, R. Korona, J. A. G. M. de Visser, Rapid multiplelevel coevolution in experimental populations of yeast killer and nonkiller strains.

Evolution. 70, 1342-1353 (2016). 
14. S. W. Buskirk, A. B. Rokes, G. I. Lang, Adaptive evolution of nontransitive fitness in yeast. Elife. 9 (2020), doi:10.7554/elife.62238.

15. P. J. Boynton, The ecology of killer yeasts: Interference competition in natural habitats. Yeast. 36, 473-485 (2019).

16. B. Becker, M. J. Schmitt, Yeast killer toxin k28: Biology and unique strategy of host cell intoxication and killing. Toxins (Basel). 9, 1-15 (2017).

17. J. S. Bloom, J. Boocock, S. Treusch, M. J. Sadhu, L. Day, H. Oates-Barker, L. Kruglyak, Rare variants contribute disproportionately to quantitative trait variation in yeast. Elife. 8 (2019), doi:10.7554/eLife.49212.

18. S. L. Chang, J. Y. Leu, T. H. Chang, A population study of killer viruses reveals different evolutionary histories of two closely related Saccharomyces sensu stricto yeasts. Mol. Ecol. 24, 4312-4322 (2015).

19. M. D. Pieczynska, J. A. G. M. de Visser, R. Korona, Incidence of symbiotic dsRNA "killer" viruses in wild and domesticated yeast. FEMS Yeast Res. 13, 856-859 (2013).

20. L. R. Fredericks, M. D. Lee, A. M. Crabtree, J. M. Boyer, E. A. Kizer, N. T. Taggart, C. R. Roslund, S. S. Hunter, C. B. Kennedy, C. G. Willmore, N. M. Tebbe, J. S. Harris, S. N. Brocke, P. A. Rowley, The Species-Specific acquisition and diversification of a K1-like family of killer toxins in budding yeasts of the saccharomycotina. PLoS Genet. 17, 1-24 (2021).

21. F. Breinig, T. Sendzik, K. Eisfeld, M. J. Schmitt, Dissecting toxin immunity in virusinfected killer yeast uncovers an intrinsic strategy of self-protection. Proc. Natl. Acad. Sci. 103, 3810-3815 (2006).

22. G. Philliskirk, T. W. Young, The occurrence of killer character in yeasts of various genera. Antonie Van Leeuwenhoek. 41, 147-151 (1975).

23. T. Nakayashiki, C. P. Kurtzman, H. K. Edskes, R. B. Wickner, Yeast prions [URE3] and [PSI+] are diseases. Proc. Natl. Acad. Sci. U. S. A. 102, 10575-10580 (2005).

24. J. S. Bloom, I. M. Ehrenreich, W. T. Loo, T.-L. V Lite, L. Kruglyak, Finding the sources of missing heritability in a yeast cross. Nature. 494, 234-237 (2013).

25. R. Poirey, L. Despons, V. Leh, M. J. Lafuente, S. Potier, J. L. Souciet, J. C. Jauniaux, Functional analysis of the Saccharomyces cerevisiae DUP240 multigene family reveals membrane-associated proteins that are not essential for cell viability. Microbiology. 148, 2111-2123 (2002).

26. V. Leh-Louis, B. Wirth, S. Potier, J. L. Souciet, L. Despons, Expansion and contraction of the DUP240 multigene family in Saccharomyces cerevisiae populations. Genetics. 167, 1611-1619 (2004).

27. F. W. Albert, D. Muzzey, J. S. Weissman, L. Kruglyak, Genetic Influences on Translation in Yeast. PLoS Genet. 10, e1004692 (2014).

28. S. Y. Carroll, P. C. Stirling, H. E. Stimpson, E. Giesselmann, M. J. Schmitt, D. G. Drubin, A yeast killer toxin screen provides insights into $\mathrm{a} / \mathrm{b}$ toxin entry, trafficking, and killing mechanisms. Dev. Cell. 17, 552-560 (2009). 
29. F. Breinig, D. J. Tipper, M. J. Schmitt, Krelp, the plasma membrane receptor for the yeast K1 viral toxin. Cell. 108, 395-405 (2002).

30. J. Peter, M. De Chiara, A. Friedrich, J.-X. Yue, D. Pflieger, A. Bergstrom, A. Sigwalt, B. Barre, K. Freel, A. Llored, C. Cruaud, K. Labadie, J.-M. Aury, B. Istace, K. Lebrigand, P. Barbry, S. Engelen, A. Lemainque, P. Wincker, G. Liti, J. Schacherer, Genome evolution across 1,011 Saccharomyces cerevisiae isolates. Nature (2018), doi:10.1038/s41586-0180030-5.

31. L. Käll, A. Krogh, E. L. L. Sonnhammer, A combined transmembrane topology and signal peptide prediction method. J. Mol. Biol. 338, 1027-1036 (2004).

32. R. N. McLaughlin, H. S. Malik, Genetic conflicts: The usual suspects and beyond. J. Exp. Biol. 220 (2017), pp. 6-17.

33. Z. Yang, PAML 4: Phylogenetic analysis by maximum likelihood. Mol. Biol. Evol. 24, 1586-1591 (2007).

34. Z. L. Newman, M. P. Printz, S. Liu, D. Crown, L. Breen, S. Miller-Randolph, P. Flodman, S. H. Leppla, M. Moayeri, Susceptibility to anthrax lethal toxin-induced rat death is controlled by a single chromosome 10 locus that includes rNlrp1. PLoS Pathog. 6, 1-8 (2010).

35. T. Sandmann, J. M. Herrmann, J. Dengjel, H. Schwarz, A. Sprang, Suppression of Coatomer Mutants by a New Protein Family with COPI and COPII Binding Motifs in Saccharomyces cerevisiae. Mol. Biol. Cell. 14, 3097-3113 (2003).

36. C. MacDonald, J. A. Payne, M. Aboian, W. Smith, D. J. Katzmann, R. C. Piper, A Family of Tetraspans Organizes Cargo for Sorting into Multivesicular Bodies. Dev. Cell. 33, 328342 (2015).

37. J. Jumper, R. Evans, A. Pritzel, T. Green, M. Figurnov, O. Ronneberger, K. Tunyasuvunakool, R. Bates, A. Žídek, A. Potapenko, A. Bridgland, C. Meyer, S. A. A. Kohl, A. J. Ballard, A. Cowie, B. Romera-Paredes, S. Nikolov, R. Jain, J. Adler, T. Back, S. Petersen, D. Reiman, E. Clancy, M. Zielinski, M. Steinegger, M. Pacholska, T. Berghammer, S. Bodenstein, D. Silver, O. Vinyals, A. W. Senior, K. Kavukcuoglu, P. Kohli, D. Hassabis, Highly accurate protein structure prediction with AlphaFold. Nature. 596, 583-589 (2021).

38. M. J. Schmitt, D. J. Tipper, K28, a unique double-stranded RNA killer virus of Saccharomyces cerevisiae. Mol. Cell. Biol. 10, 4807-4815 (1990).

39. R. B. Wickner, "Killer character" of Saccharomyces cerevisiae: curing by growth at elevated temperature. J. Bacteriol. 117, 1356-1357 (1974).

40. D. M. Becker, V. Lundblad, in Current protocols in molecular biology, F. M. Ausubel, Ed. (2001), p. Unit13.7.

41. M. Dunham, M. Gartenbeg, G. W. Brown, Methods in Yeast Genetics and Genomics A CSHL Course Manual (Cold Spring Harbor Laboratory Press, Cold Spring Harbor, New York, 2014;

https://www.cshlpress.com/default.tpl?cart=1634668643500627115\&fromlink=T\&linkact ion=full\&linksortby=oop_title\&--eqSKUdatarq=1063). 
42. D. R. Woods, E. A. Bevan, Studies on the Nature of the Killer Factor Produced by Saccharomyces cerevisiae. Microbiology. 51, 115-126 (1968).

43. D. C. Amberg, D. Burke, J. N. Strathern, Methods in yeast genetics : a Cold Spring Harbor Laboratory course manual (Cold Spring Harbor Laboratory Press, 2005).

44. M. Lynch, B. Walsh, in Genetics and Analysis of Quantitative Traits (1998), pp. 319-532.

45. P. M. Visscher, R. Thompson, C. S. Haley, Confidence Intervals in QTL Mapping by Bootstrapping. Genetics. 143 (1996).

46. A. Löytynoja, Phylogeny-aware alignment with PRANK. Methods Mol. Biol. 1079, 155170 (2014).

47. S. L. Kosakovsky Pond, D. Posada, M. B. Gravenor, C. H. Woelk, S. D. W. Frost, GARD: a genetic algorithm for recombination detection. Bioinformatics. 22, 3096-3098 (2006).

48. M. N. Price, P. S. Dehal, A. P. Arkin, FastTree 2 - Approximately maximum-likelihood trees for large alignments. PLoS One. 5, e9490 (2010).

49. H. Wickham, ggplot2: Elegant Graphics for Data Analysis. (Springer-Verlag, New York, NY, 2016).

50. E. Paradis, K. Schliep, ape 5.0: an environment for modern phylogenetics and evolutionary analyses in R. Bioinformatics. 35, 526-528 (2019).

51. F. Sievers, A. Wilm, D. Dineen, T. J. Gibson, K. Karplus, W. Li, R. Lopez, H. McWilliam, M. Remmert, J. Söding, J. D. Thompson, D. G. Higgins, Fast, scalable generation of high-quality protein multiple sequence alignments using Clustal Omega. Mol. Syst. Biol. 7, 539 (2011).

52. T. Krassowski, A. Y. Coughlan, X. X. Shen, X. Zhou, J. Kominek, D. A. Opulente, R. Riley, I. V. Grigoriev, N. Maheshwari, D. C. Shields, C. P. Kurtzman, C. T. Hittinger, A. Rokas, K. H. Wolfe, Evolutionary instability of CUG-Leu in the genetic code of budding yeasts. Nat. Commun. 9 (2018), doi:10.1038/s41467-018-04374-7.

53. I. Belda, J. Ruiz, A. Alonso, D. Marquina, A. Santos, The biology of pichia membranifaciens killer toxins. Toxins (Basel). 9 (2017), , doi:10.3390/toxins9040112.

54. J. Zorg, S. Kilian, F. Radler, Killer toxin producing strains of the yeasts Hanseniaspora uvarum and Pichia kluyveri. Arch. Microbiol. 149, 261-267 (1988).

55. B. Wirth, V. L. Louis, S. Potier, J. L. Souciet, L. Despons, Paleogenomics or the search for remnant duplicated copies of the yeast DUP240 gene family in intergenic areas. Mol. Biol. Evol. 22, 1764-1771 (2005).

56. Y. Takahashi, J. Mizoi, A. Toh-e, Y. Kikuchi, Yeast Ulp1, an Smt3-specific protease, associates with nucleoporins. J. Biochem. 128, 723-725 (2000). 


\section{Acknowledgments}

We thank Keith Kozminski, Leonid Kruglyak, Peter Stirling, Frank Albert, Helen Murphy, and members of the Sadhu and Kruglyak labs for helpful discussion. We thank David Drubin, Leonid Kruglyak, and Reed Wickner for strains and plasmids.

\section{Funding}

National Institutes of Health grant 1ZIAHG200401 (IA, SMG, MJS)

National Institutes of Health grant 5T32GM007185 (GU)

National Institutes of Health grant 1ZIAHG200362 (DS)

Howard Hughes Medical Institute (JSB)

\section{Author contributions}

Conceptualization: MJS

Methodology: IA, SMG, GU, DS, JSB, MJS

Investigation: IA

Formal analysis: IA

Visualization: IA, MJS

Supervision: MJS

Resources: JSB

Writing - original draft: IA, MJS

Writing - reviewing \& editing: IA, SMG, MJS

\section{Competing interests}

Authors declare no competing interests.

\section{Data and materials availability}

All data and code will be archived in a permanent, independent repository prior to publication. Currently, all data and code are located at https://github.com/ilya-andreev2/killer-virus. 
A

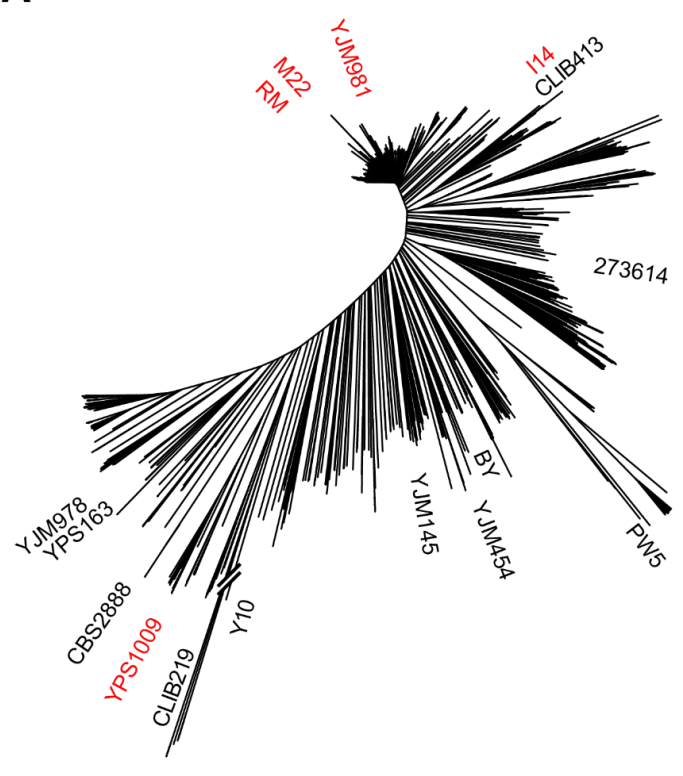

B
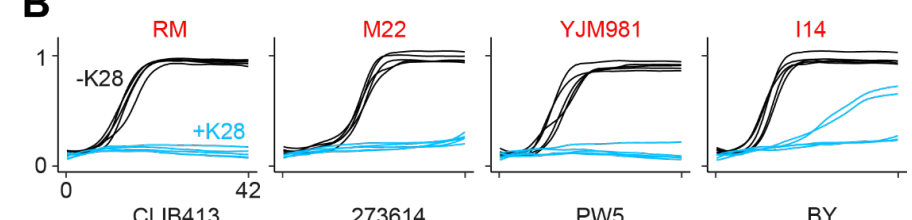

BY
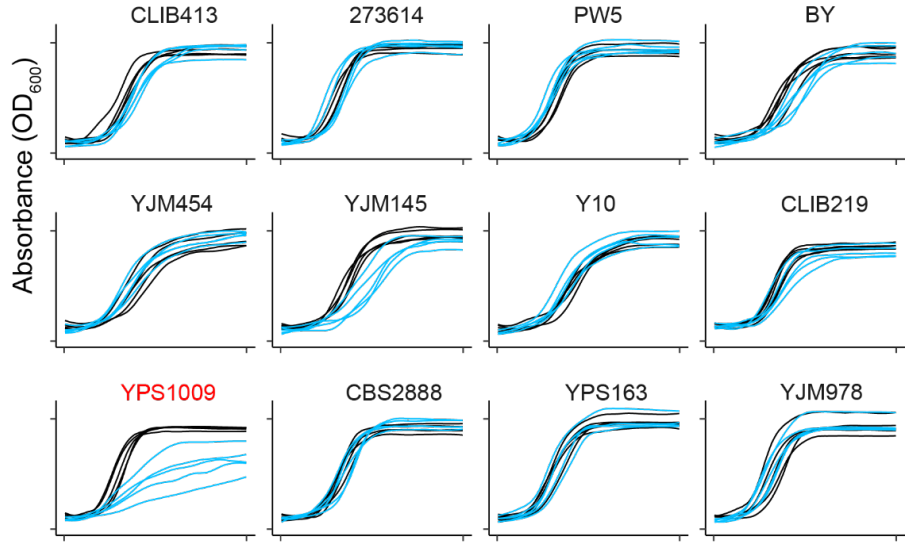

Time (h)

Figure 1. High natural variation in K28 resistance. (A) Neighbor-joining phylogenetic tree of 1,011 budding yeast isolates (30), highlighting the 16 strains selected for our panel. Name coloring reflects K28 killer toxin resistance, with red labels for sensitive strains and black labels for resistant strains, as determined in part B. (B) Growth curves of 16 diverse $S$. cerevisiae strains in minimal media with or without K28 (blue and black, respectively; $n=5$ ). K28 resistance was quantified as the ratio of the areas under the growth curves in media containing or lacking $\mathrm{K} 28$ ( $\left.\mathrm{AUC}_{+\mathrm{K} 28} / \mathrm{AUC}_{-\mathrm{K} 28}\right)$ (fig. S1). Statistical analysis was performed using one-way analysis of variance (ANOVA) followed by Tukey's post-hoc HSD test, and identified five strains as K28-sensitive (strain names in red) in comparisons with BY ( $P$ adjusted $<6.6 \times 10^{-6}$ ). 
A

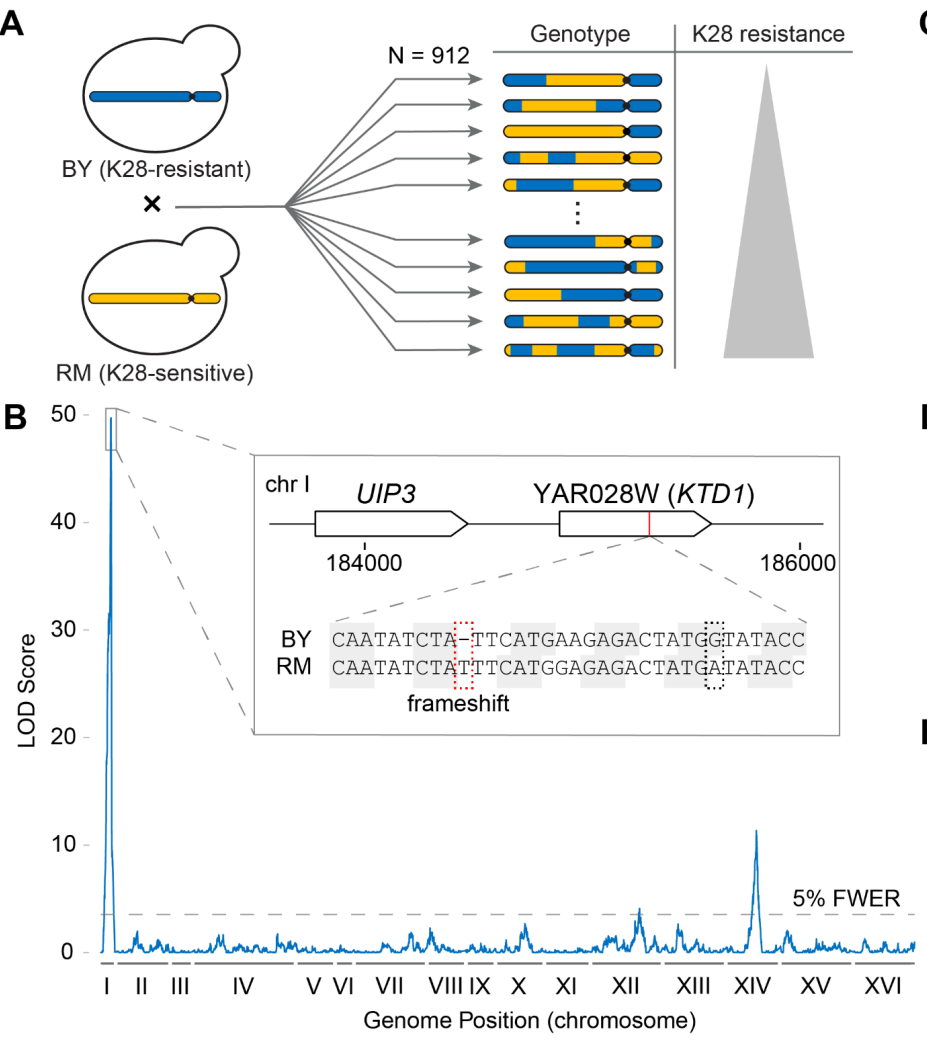

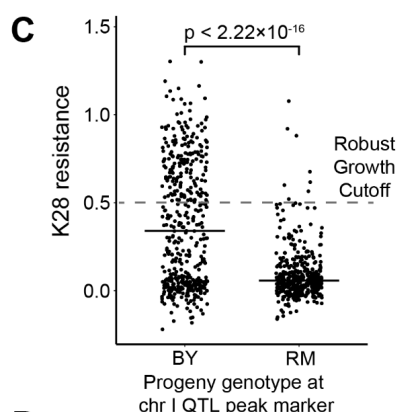

D
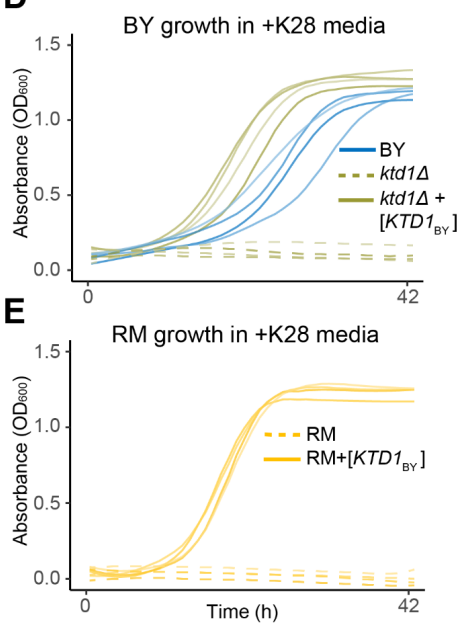

Figure 2. QTL mapping reveals YAR028W (KTD1) as a major genetic factor in killer toxin

resistance. (A) Schematic representation of the workflow leading up to QTL mapping. 912 recombinant haploid progeny from a cross between BY and RM were assayed for K28 resistance, measured as $\mathrm{AUC}_{+\mathrm{K} 28} / \mathrm{AUC}_{-\mathrm{K} 28 .}$ (B) QTL mapping results. Shown is the degree of association of a genomic locus with K28 resistance phenotype, measured as the LOD (logarithm of the odds) score, plotted against genomic coordinates. Three significant QTLs were found above the 5\% family-wise error rate (FWER) significance threshold (LOD $=3.55$, gray dashed line). The inset shows the genomic context of the QTL peak on chromosome I. (C) Phenotypic distribution of $912 \mathrm{BY} \times \mathrm{RM}$ progeny grouped by their genotype at the peak marker for the chr I QTL. $P<2.22 \times 10^{-16}$ by Welch's two-sample $t$-test. The solid horizontal black lines denote mean phenotypes. We used an $\mathrm{AUC}_{+\mathrm{K} 28} / \mathrm{AUC}_{-\mathrm{K} 28}$ cutoff of 0.5 to define robust growth. (D) Growth of BY with an empty vector, and of BY yar028w $\Delta(k t d 1 \Delta)$ carrying either an empty vector or

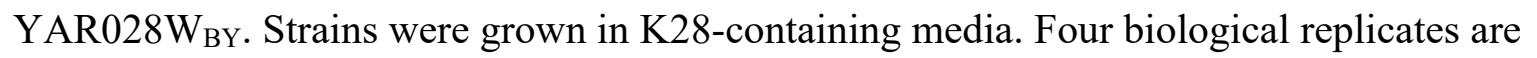
shown in each plot. (E) Growth of RM carrying either an empty vector or the YAR028W $\mathrm{WY}_{\mathrm{BY}}$ $\left(K T D 1_{\mathrm{BY}}\right)$ allele. In D and E, strains with YAR028W $\mathrm{WY}_{\mathrm{BY}}\left(K T D 1_{\mathrm{BY}}\right)$ were significantly more K28resistant than those without, $P<0.005$ by Welch's two-sample one-tailed $t$-test (fig. S6). 


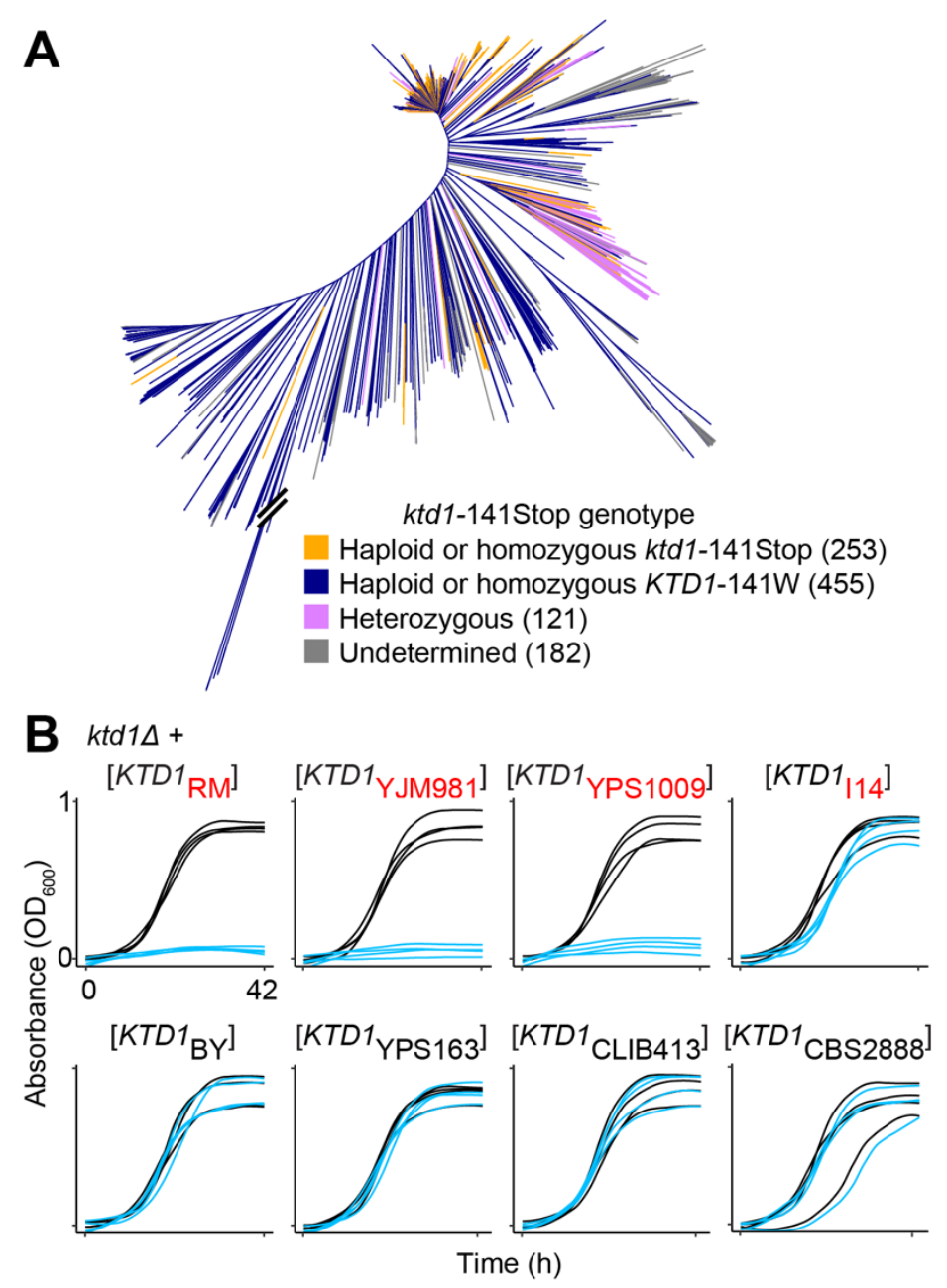

Figure 3. Analysis of KTD1 alleles in the yeast population. (A) Distribution of the ktdl141Stop mutation among 1,011 yeast isolates (30). (B) Growth curves of strains carrying the indicated KTDl allele in the BY ktdl $1 \Delta$ background; blue and black growth curves correspond to strains grown in minimal media with or without K28, respectively $(n=4)$. The subscript of the allele label indicates the strain in which that KTD1 allele was found, while color indicates that strain's phenotype (black, resistant; red, sensitive). ANOVA followed by Tukey's HSD (fig. S8) identified the first three alleles as significantly less resistant than the last five $\left(P\right.$ adjusted $<5 \times 10^{-}$ 14 for all between-group comparisons). 
A

\section{䨪}

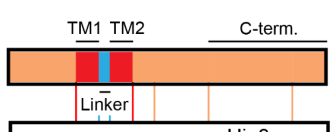

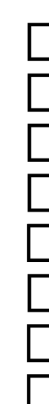

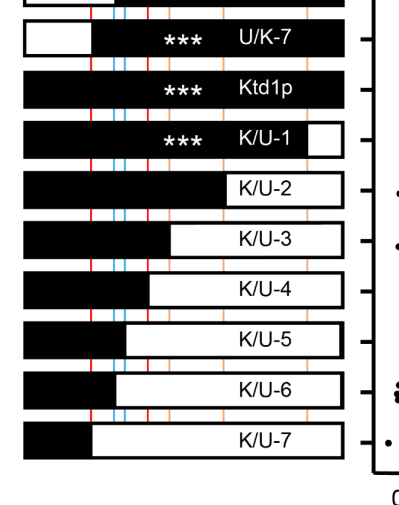

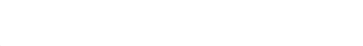

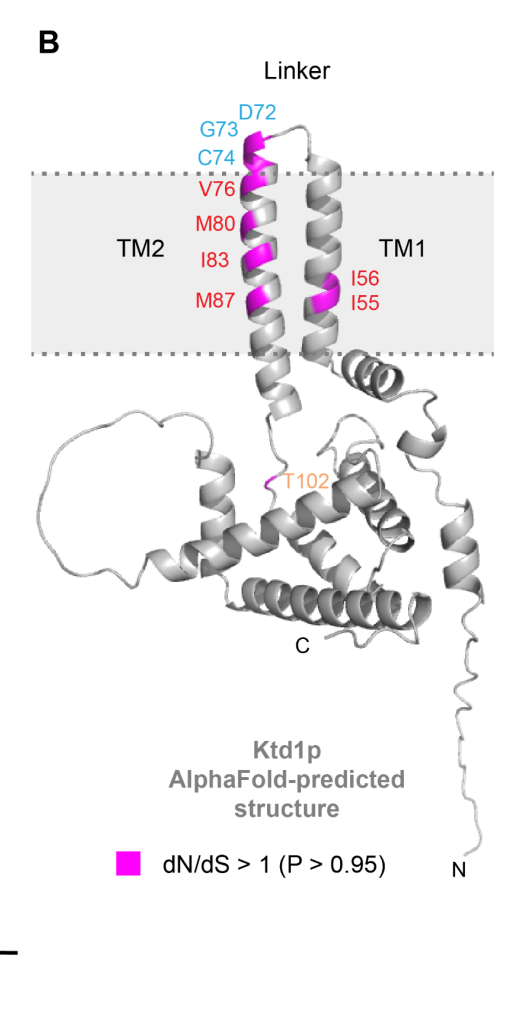

Figure 4. Ktd1p protein analysis. (A) K28 resistance phenotypes of chimeras between Ktd1p and Uip3p expressed in the BY ktdl $\Delta$ background. White segments denote regions of chimeras derived from the non-protective Uip3p, and black segments denote regions derived from the protective Ktd1p. Four biological replicates are shown for each chimera's K28 resistance phenotype, measured as $\mathrm{AUC}_{+\mathrm{K} 28} / \mathrm{AUC}_{-\mathrm{K} 28}$ from the growth curves in fig. S10, with vertical bars denoting the sample mean. $* * * P$ adjusted $<0.001$ in comparison to Uip3p (ANOVA followed by Tukey's HSD). (B) Sites of positive selection in Ktd1p. Sites having a greater than 0.95 probability of $\mathrm{dN} / \mathrm{dS}$ above 1 are highlighted in magenta. Protein structure of Ktd1p was predicted by AlphaFold (37). The colors of the amino acid labels correspond to the coloring of the topological domains of Ktd1p in part A, as defined by Poirey, et al. (25). 


\section{Materials and Methods}

\section{Strains}

Strains, plasmids, and oligonucleotide sequences used in this study are listed in Tables S6, S7, and S8, respectively. All constructed plasmids were sequence-verified using Sanger sequencing (Eurofins Genomics, Louisville, KY, USA).

The 16-isolate panel of diverse $S$. cerevisiae strains, MSY24-MSY39, was composed of stable haploid strains made by Bloom, et al. (17) and were gifts from Leonid Kruglyak, as well as MSY1 and MSY8 and the panel of BY $\times$ RM segregants (24). MS300c (MSY20) and 192.2d (MSY21) were gifts from David Drubin (28).

We generated a diploid K28-secreting strain for production of toxin-containing supernatant (described in the section "Preparation of Toxic and Non-toxic Supernatants" below). As this supernatant was to be applied to haploid cells of either a or alpha mating type, we designed our K28-secreting strain to be diploid so that it would not release mating pheromone into the media. A K28 hypersecretor, MS300c (MATalpha leu2 ski2-2 \{M28 infected\}) (38), was mated to ski24

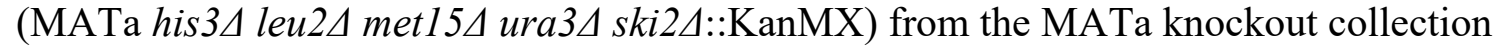
(Transomic, Huntsville, AL) to produce a hypersecretor diploid (ski24/ski2-2) strain, MSY52, that is infected with the M28 virus and preserves the hypersecreting phenotype due to the absence of SKI2 function.

We generated a virus-cured strain for production of non-toxic control media. Virus curing was performed by growth of MSY52 at high temperature (39). MSY52 was pre-grown in liquid YPD media overnight at $37 \mathrm{C}$ (elevated) or $30 \mathrm{C}$ (control). Cultures were diluted in fresh YPD to a density of approximately 500 cells $/ 200 \mu \mathrm{L}$, at which point $200 \mu \mathrm{L}$ of cultures were pipetted onto YPD agar plates. After a 2-day incubation at respective temperatures (30 or $37 \mathrm{C}$ ), colonies were replica-plated onto Methylene Blue Agar (MBA) plates ( $\mathrm{pH} 4.7$ ) seeded with lawns of the K28hypersensitive 192.2d strain (MSY21). All $30 \mathrm{C}$ control colonies showed killer activity, indicated by the inability of $192.2 \mathrm{~d}$ to grow in their vicinity. Several colonies from the $37 \mathrm{C}$ plate no longer exhibited killer phenotype, one of which was selected and named MSY53. Absence of M28 virus was confirmed by virus typing assay (see below).

uip34, ktd1A (MSY123), and mnn2A were taken from the MATa knockout collection.

The remaining strains in Table S6 were generated by transforming ktd1 1 , mnn2 2 , RM (MSY8), or BY (MSY1) with the plasmids described in Table S7 using standard lithium acetate transformation procedures (40).

\section{Stock Solutions and Media}

Phosphate-Citrate Buffer ( $\mathrm{pH} 4$.7) was prepared by first dissolving $56.88 \mathrm{~g} \mathrm{~K}_{2} \mathrm{HPO}_{4}$ into $200 \mathrm{~mL}$ distilled water and subsequently titrating with approximately $30 \mathrm{~g}$ citric acid until $\mathrm{pH} 4.7$ was reached. The solution was sterilized by autoclaving for $20 \mathrm{~min}$. Crystals may form over long periods of storage, which can be redissolved by heating the buffer to $80 \mathrm{C}$ for 20-30 min, stirring, and cooling. 
Specialized low-pH CSM minimal media for production of K28 killer toxin, CSM pH $4.7+$ $0.05 \%$ gelatin, was prepared by adding pre-mixed CSM powders (Sunrise Science, Knoxville, $\mathrm{TN})$ and YNB (BD, Franklin Lakes, New Jersey, USA) according to manufacturer instructions, dextrose to $2 \%$ (MP Biomedicals, Irvine, CA), and adding back uracil and leucine to the concentrations specified in Dunham, et al. (41). $\mathrm{pH}$ was adjusted with $112 \mathrm{~mL}$ of $\mathrm{pH} 4.7$ phosphate-citrate buffer per $1 \mathrm{~L}$ media. For additional killer toxin stability, media was supplemented with $0.05 \%$ type B gelatin (MilliporeSigma, Burlington, MA, USA, Cat. \#G9391$100 \mathrm{G}$ ) as per Woods and Bevan (42). The mixture was heat-stirred for $2 \mathrm{~h}$ to allow gelatin to dissolve. All CSM media were sterilized using $0.22 \mu \mathrm{m}$ polyethersulfone membrane filters (MilliporeSigma).

For use with supernatants, as described below, we made concentrated replenishment minimal media, 5xCSM pH 4.7, either with or without histidine as appropriate for the experiment. These media were prepared by dissolving either 0.8375 g CSM-Leu-Ura or 0.8125 g CSM-His-Leu-Ura powders (Sunrise Biosciences) in $222 \mathrm{~mL}$ distilled $\mathrm{H}_{2} \mathrm{O}$, along with $125 \mathrm{mg}$ leucine, $25 \mathrm{mg}$ uracil, $8.375 \mathrm{~g} \mathrm{YNB}$, and $25 \mathrm{~g}$ dextrose. $\mathrm{pH}$ was adjusted with $28 \mathrm{~mL}$ phosphate-citrate buffer ( $\mathrm{pH}$ 4.7). The solutions were stirred for approximately $20 \mathrm{~min}$ to ensure full dissolution of uracil crystals and subsequently filter-sterilized.

YPD media contained 1\% yeast extract (Thermo Fisher Scientific, Waltham, MA, USA), 2\% peptone (BD), and $2 \%$ dextrose, and was sterilized by autoclaving. When used for plates, the media additionally contained $2 \%$ agar.

YPD-based Methylene Blue Agar (MBA) plates ( $\mathrm{pH} 4.7)$ were prepared as described in Amberg et al. (43). Briefly, $1 \%$ yeast extract, $2 \%$ peptone, $2 \%$ glucose, and $2 \%$ agar were dissolved in $415 \mathrm{~mL}$ distilled water and autoclaved for $20 \mathrm{~min}$. Following autoclaving, media was supplemented with sterile solutions of $25 \mathrm{~mL} 40 \%$ glucose, $4.2 \mathrm{~mL}$ of $4 \mathrm{mg} / \mathrm{mL}$ methylene blue dye (MilliporeSigma), and $56 \mathrm{~mL}$ phosphate-citrate buffer of $\mathrm{pH}$ 4.7. Correct $\mathrm{pH}$ was confirmed using a $\mathrm{pH}$ probe after buffer addition.

\section{Preparation of Toxic and Non-toxic Supernatants}

Single colonies of MSY52 (diploid K28-secretor) or MSY53 (virus-free diploid) were separately inoculated into $200 \mathrm{~mL}$ of CSM pH $4.7+0.05 \%$ gelatin and incubated for $24-48 \mathrm{~h}$ at $23 \mathrm{C}, 70$ RPM. These conditions were necessary for generating stable, high-activity K28 killer toxin. For experiments with strains carrying a HIS3 plasmid, CSM-His was used instead of CSM for supernatant preparations. Cultures were filtered with $0.22 \mu \mathrm{m}$ polyethersulfone membrane filters into pre-chilled glass bottles, producing the toxic (MSY52) and non-toxic (MSY53) supernatants.

\section{Liquid Growth Assay for Killer Toxin Resistance}

Single colonies of yeast strains were inoculated and pre-grown in $100 \mu \mathrm{L}$ CSM or CSM-His (pH 7.0) for $24 \mathrm{~h}$ in CORNING 96-well plates prior to the experiment. $1.5 \mu \mathrm{L}$ of saturated yeast cultures were transferred into $160 \mu \mathrm{L}$ of either the toxic or non-toxic supernatant, supplemented with $40 \mu \mathrm{L} 5 \mathrm{xCSM}$ pH 4.7 (with or without histidine) to replenish spent nutrients, for a total volume of $201.5 \mu \mathrm{L}$ in each well. Strains were randomly distributed across the plate to avoid 
confounding of strain identity with position on plate. The one exception is the experiment comparing toxin sensitivity of uip3 $\Delta$ and $k t d 1 \Delta$ to WT (fig. S5), in which each strain occupied a specific row on the plate. Absorbance $\left(\mathrm{OD}_{600}\right)$ of each well was measured on a SPECTROstar Omega microplate reader equipped with a plate stacker (BMG Labtech, Ortenberg, Germany) over a period of 2-3 days at ambient temperature ( $25 \mathrm{C})$ with $30 \mathrm{~s}$ of shaking at $600 \mathrm{RPM}$ prior to each plate reading. Reads were taken with variable frequency depending on the number of plates being read, with cycle time ranging from 8 to 104 minutes. For each strain in an individual well, the K28 toxin resistance phenotype was calculated, following blank correction, as the ratio of the area under the growth curve in toxic media $\left(\mathrm{AUC}_{+\mathrm{K} 28}\right)$ to the area under the growth curve in non-toxic media ( $\mathrm{AUC}_{-\mathrm{K} 28}$ ), i.e. $\mathrm{AUC}_{+\mathrm{K} 28} / \mathrm{AUC}_{-\mathrm{K} 28}$. Values close to 0 indicate low killer toxin resistance, while values close to 1 correspond to high resistance.

\section{Killer spotting assay}

$4 \mathrm{~mL}$ YPD cultures of MSY21, MSY52-53, and MSY24-39 were grown overnight, with MSY39 (ade-) supplemented with $1 \%$ adenine. $2 \times 10^{7}$ or $4 \times 10^{7}$ cells of K28-hypersensitive MSY21 (192.2d) were uniformly spread on 10-cm MBA agar plates, with 3 replicate plates for each plating density. Cultures of MSY52 (K28-secreting control), MSY53 (virus-free control), and MSY24-39 (the 16-isolate panel) were pelleted at $3000 \mathrm{rpm}$ and resuspended in fresh YPD to make a $\sim 50 \% \mathrm{v} / \mathrm{v}$ cell slurry, as previously described (28). $150 \mu \mathrm{L}$ of these slurries were pipetted into wells of a 96-well plate and pinned with a VP407AH metal replicator (V\&P Scientific, San Diego, CA) to transfer approximately $3 \mu \mathrm{L}$ of slurry onto the previously MSY21-seeded MBA plates. Each spot of pinned cells was imaged through microscope oculars using the back camera of a Galaxy S10e mobile phone (Samsung, Seoul, South Korea) with Open Camera v1.49.1 software, which allowed imaging of colonies at fixed exposure and white balance within an individual plate.

\section{Viral RNA typing assay}

To assay for presence of M28 virus in a given strain, RT-PCR-based virus typing was performed as described by Chang, et al. (18). Briefly, following isolation of total RNA with the Qiagen RNeasy Mini Kit (Qiagen, Valencia, CA, USA), cDNA was synthesized by incubating RNA for $2 \mathrm{~h}$ at $37 \mathrm{C}$ using the High-Capacity cDNA Reverse Transcription Kit (Applied Biosystems, Foster City, CA, USA). Afterwards, PCR with Kapa HiFi HotStart ReadyMix (Roche, Basel, Switzerland) was performed on the cDNA using M28 virus-specific primer pairs: oIA9/oIA10, oIA11/oIA12, and oIA13/oIA14 with expected fragment sizes of 253, 180, and $350 \mathrm{bp}$, respectively. These primers correspond exactly to M28-F1/R1, M28-F2/R2, and M28-F3/R3 primers used by Chang, et al. Presence of M28 virus was characterized by strong PCR bands at expected amplicon lengths. A band of low intensity at $650 \mathrm{bp}$ appeared in several experiments, which we deemed an artifact because its presence was irrespective of the particular PCR primer pair.

\section{QTL Mapping}

QTL mapping was performed on 960 haploid F1 segregants generated from a cross between BY and RM, which were a gift from Leonid Kruglyak (24). The segregants, arrayed in ten 96-well plates, were transferred in parallel with a disposable plastic pinner into $200 \mu \mathrm{L}$ CSM pH $4.7+$ $0.05 \%$ gelatin media either with K28 (10 plates) or without K28 (additional 10 plates), as described in the "Liquid Growth Assay for Killer Toxin Resistance" section above. Growth was 
measured in parallel over 63 hours on a SPECTROstar Omega microplate reader equipped with a plate stacker. The $\mathrm{K} 28$ resistance of each segregant was quantified as the ratio of $\mathrm{AUC}+\mathrm{K} 28 / \mathrm{AUC}$. K28, as described above. QTL mapping was performed by calculating the logarithm-of-odds (LOD) score for each of 28,220 biallelic markers, defined as

$$
L O D=\frac{-N}{2 * \ln (10)} \ln \left(1-r^{2}\right)
$$

where $N=912$ is the number of segregants after filtering out ill-behaved segregants, and $r$ is the Pearson correlation between the K28 resistance phenotype and the genotype of each segregant at that biallelic marker; see page 454 of Lynch and Walsh (44). The genotypes are coded with -1 representing that the segregant had the $\mathrm{RM}$ allele and +1 signifying the $\mathrm{BY}$ allele, as determined by Bloom, et al. (24). The significance threshold was determined by a permutation test: QTL mapping was done 1000 times on permutations of the strain phenotypes relative to the strain genotypes, and the top LOD score was taken from each mapping. Among these LOD scores, the 950th highest value was taken as the 5\% family-wise error rate (FWER) threshold for significance. Three QTLs were detected with peak LOD scores above this threshold. 95\% confidence intervals for the location of the peak of these QTLs were determined by bootstrap with 1000 samplings with replacement (45), taking the peak marker per QTL-containing chromosome from each bootstrap mapping, ordering them from left to right, and determining the confidence interval as the span between the 2.5 th and 97.5 th percentile bootstrap peaks.

\section{Cloning of KTD1 alleles}

$K T D 1$ alleles tested in figures 2D, 2E, and 3B were amplified from genomic DNA using PfuUltraII Fusion HS DNA Polymerase (Agilent, Santa Clara, CA, USA) and primers listed in Table S8. Genomic DNA was isolated using DNeasy Blood \& Tissue Kit (Qiagen) and following Qiagen's Supplementary Protocol "Purification of total DNA from yeast using the DNeasy Blood \& Tissue Kit". Primers used for amplification are listed in Table S8. Amplicons were Gibson assembled (New England Biolabs, Ipswich, MA, USA) with pRS313 (MSp64) digested with XbaI-HF and XhoI-HF (New England Biolabs) or with MSp101 (KTD1 1 BY) digested with NotI-HF and ApaI-HF (New England Biolabs).

\section{Chimeragenesis}

All chimeras between KTD1 and UIP3, as well as KTD1 and UIP3 themselves, were expressed from the KTD 1 promoter (nucleotide position -311 to -1 relative to the KTD1 start codon) and terminator (position +1 to +230 relative to the KTDl ORF). Fragments were assembled via Gibson assembly. "Insert" PCR amplicons were generated using the high-fidelity PfuUltraII Fusion HS DNA Polymerase, while the longer "plasmid" PCR amplicons were generated using Herculase II Fusion DNA Polymerase (Agilent). Primer sequences used for chimeragenesis are listed in Table S8.

To construct chimeras, first, we used the KTD1 plasmid, MSp101, to construct the UIP3 plasmid, MSp160: we Gibson assembled the UIP3 coding sequence amplified from BY genomic DNA with an amplicon of plasmid MSp101 to replace the KTD1 coding sequence with UIP3. To generate chimeras, we amplified a "plasmid" fragment from MSp101 that contained a segment of KTD1 along with the plasmid backbone. We amplified the corresponding "insert" fragment from MSp160 which contained the desired UIP3 segment. The chimera-specific primers used to produce each plasmid-insert pair of PCR amplicons gave them approximately $20 \mathrm{bp}$ of homology 
at each end. These fragments were Gibson assembled. Chimera transition points were selected to according to the conservation- and topology-based domains of DUP240 proteins defined by Poirey, et al. (25). Each plasmid was transformed into BY ktdl $\Delta$ and tested as described in the section "Killer Toxin Resistance Assay in Liquid Media."

\section{Analysis of positive selection}

Assemblies of the genomes of the 16-isolate panel generated by Moleculo technology (Illumina, San Diego, CA, USA) were obtained from Bloom, et al. (17). The 10 DUP240 genes from the reference $S$. cerevisiae genome were used as BLASTn (BLAST+ v2.10.0) queries against each of the assembled genomes using default search parameters. Hits were recursively added to the search query until no new hits were found, leading to a set of 15 new DUP240 orthologs, none of which had greater than $96 \%$ nucleotide identity to another DUP240. Sequences are available on GitHub and have been submitted to the Saccharomyces Genome Database.

A codon-based alignment of the DUP240 genes was generated using PRANK (v.170427) (46) with the gaprate parameter set to 0.000001 and a gap extension penalty of 0.001 . As the codeML module of PAML does not estimate $\mathrm{dN} / \mathrm{dS}$ values for codons aligned to gaps, DUP240 genes that created lots of gaps in the alignment were removed, resulting in a final alignment of 18 DUP240 orthologs (fig. S11). Analysis of BLASTn results showed that some of these orthologs are recombinants, whose inferred phylogeny may be incorrect. We performed recombination analysis using GARD (47) to predict recombination breakpoints. For breakpoints that occurred in the middle of a codon, we rounded to the nearest codon boundary. Seven breakpoints were identified, which we used to break the alignment into 8 segments for further analysis.

Phylogenetic trees were generated on each segment with FastTree (2.1) (48) with -gtr -gamma options. We then used the codeml module in PAML (v 4.9j) to generate models M7 (no positive selection) and M8 (with positive selection) on each segment with the corresponding segmentspecific alignment and phylogenetic tree. The two models were compared by computing the likelihood-ratio test statistic,

$$
\lambda_{L R}=2\left[\ln \left(L_{M 8}\right)-\ln \left(L_{M 7}\right)\right]
$$

which is chi squared-distributed with two degrees of freedom. The results are summarized in Table S5.

\section{Toxin Adsorption}

To test the ability of K28 toxin to bind to the surface of yeast cells, we adapted the toxin-cell binding assay described in Carroll, et al. and Breinig, et al. $(28,29)$. Strains MSY94, 96-100, and 104 ( $n=4$ biological replicates) were grown to saturation for $48 \mathrm{~h}$ in $30 \mathrm{~mL}$ CSM-His (pH 7.0) at $30 \mathrm{C}$, shaking at $200 \mathrm{RPM}$. $200 \mathrm{~mL}$ of toxic and non-toxic supernatants were prepared as described earlier, with $24 \mathrm{~h}$ incubation time. Strain MSY26 (RM) was grown for $24 \mathrm{~h}$ in YPD. $10^{9}$ cells (50 OD 600 units) of each experimental strain were pelleted at 3000 RPM. Supernatant was mostly aspirated, leaving approximately $0.5-0.7 \mathrm{~mL}$ media in the tube. Pellet was resuspended in the remaining supernatant and placed on ice.

$5 \mathrm{~mL}$ of toxic supernatant was added to each cell suspension and incubated for $15 \mathrm{~min}$ on a nutator at approximately 1 RPM. As controls, we also incubated cell-free toxic and non-toxic supernatants. Suspensions and cell-free controls were then filtered using syringes with $0.22 \mu \mathrm{m}$ 
Nalgene syringe filters (Thermo Fisher Scientific), generating filtrates of dissolved toxin that had not adsorbed to cell surfaces. The toxin adsorption and filtration steps were done at $4 \mathrm{C}$. The degree of toxin adsorption was quantified as the area under the growth curve $(\mathrm{AUC}+\mathrm{K} 28)$ of the K28-sensitive strain RM in $160 \mu \mathrm{L}$ filtrate $+40 \mu \mathrm{L} 5 \mathrm{xCSM}$ pH 4.7 for $48 \mathrm{~h}$ (fig. S7).

\section{Software, Statistical Analysis, Data Deposition, and Data Visualization}

Statistical analysis and data visualization were performed using custom R scripts, available at https://github.com/ilya-andreev2/killer-virus. For experiments with comparisons among many strains, statistical analysis was performed using one-way ANOVA followed by Tukey's post-hoc HSD test. For experiments comparing specific pairs of strains, statistical analysis was performed with Welch's two-sample $t$-tests.

Growth curves were generated using the geom_smooth function in the R package ggplot2 (version 3.3.5) (49). Area under the curve (AUC) was calculated using the $A U C$ function (trapezoid method) from the R package DescTools v.0.99.42. Neighbor-joining phylogenetic trees of 1,011 sequenced yeast strains (30) were generated using the function bionj from the $\mathrm{R}$ package ape (version 5.3) (50). The maximum edge length was set to 0.7 to truncate a highly diverged clade of yeast strains. Jittered 1-dimensional scatter plots were generated using the ggboxplot function in R package ggpubr. Protein sequence alignments were generated in Clustal Omega (51). The structure of Ktd1p was predicted using AlphaFold (version 2.0.0) (37) and visualized in PyMOL (version 2.3.0 Open-Source), with the position of the transmembrane helices shown according to Poirey, et al. (25).

Moleculo-based genome assemblies of the strains in our 16-isolate panel are being submitted to the NCBI genome database, and non-reference DUP240 genes have been submitted to the Saccharomyces genome database (SGD) named DFP11 through DFP25 (DUP240 family protein). 


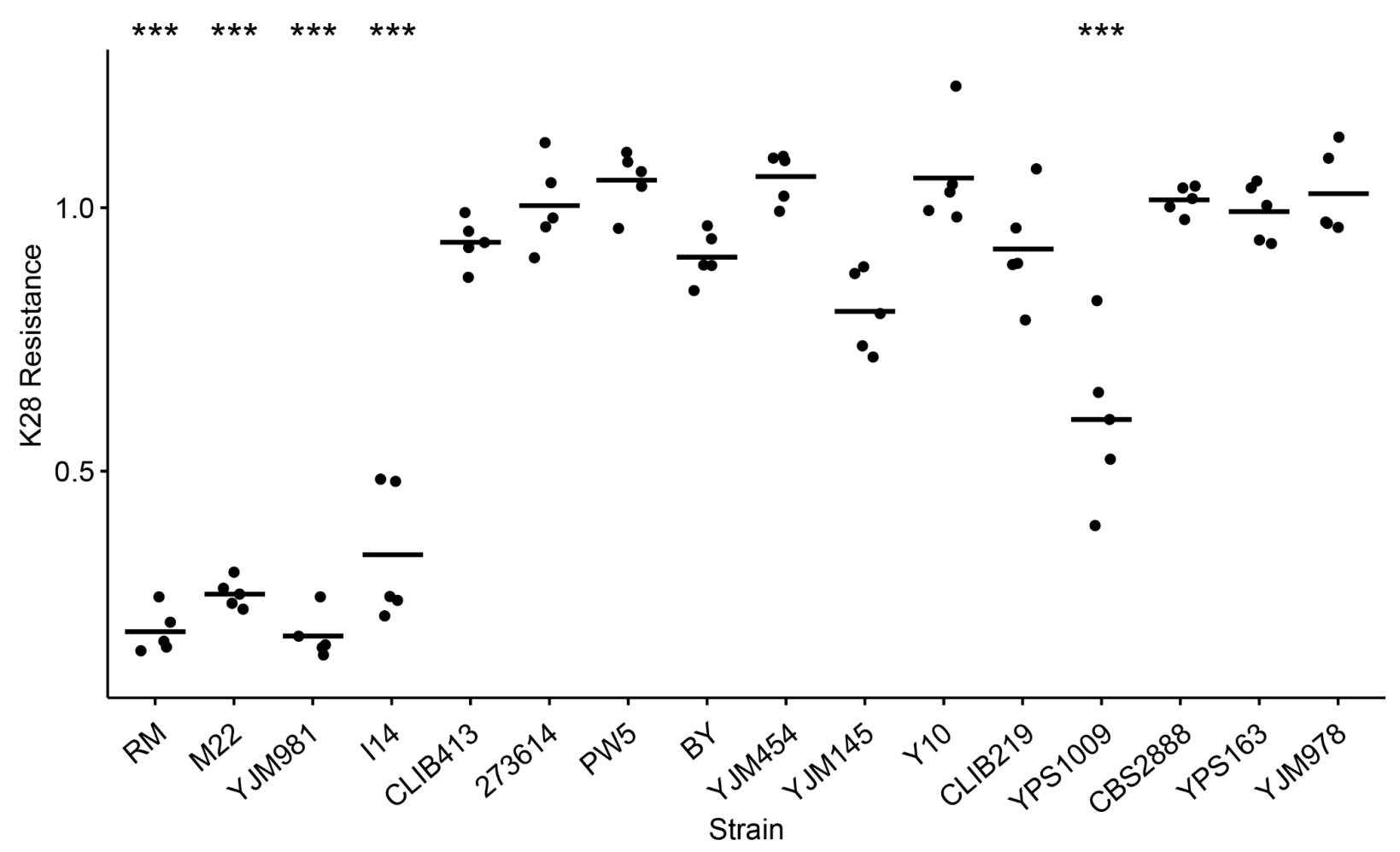

Figure S1. Statistical analysis of $\mathrm{K} 28$ resistance of 16 diverse S. cerevisiae strains.

From the growth curves in figure 1B, K28 resistance was quantified as AUC+K28 / AUC-K28 with $n=5$ biological replicates per strain. One-way ANOVA indicated a statistically significant effect of strain on K28 resistance (K28 resistance $\sim$ strain). Tukey's post-hoc HSD test was performed to test for the difference in mean K28 resistance between all pairs of strains. Strains with significantly lower $\mathrm{K} 28$ resistance are marked with asterisks $\left(* * * P<6.6 \times 10^{-6}\right.$ in comparison to BY). Horizontal bars indicate the sample means. 


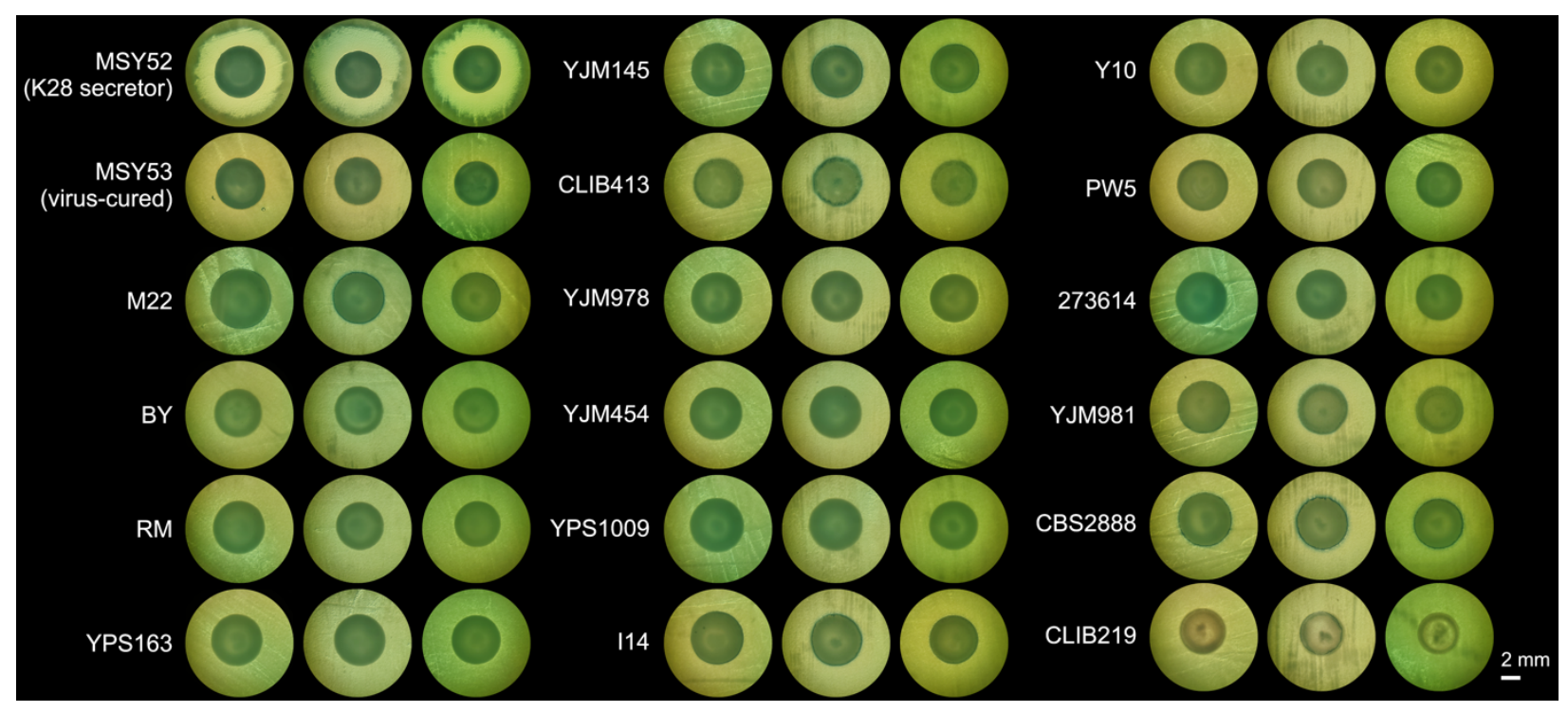

Figure S2. Phenotypic Virus Typing - Halo Assay.

The 16-isolate panel was tested for production of K28 toxin by whether they killed the hypersensitive yeast strain 192.2d. Triplicate spots of each strain were grown on a lawn of 192.2d cells; strains producing K28 will generate a halo of cleared 192.2d cells (28). MSY52, a diploid ski24 strain infected by M28, was spotted as a positive control; MSY53, a virus-cured derivative of MSY52, was spotted as a negative control. 

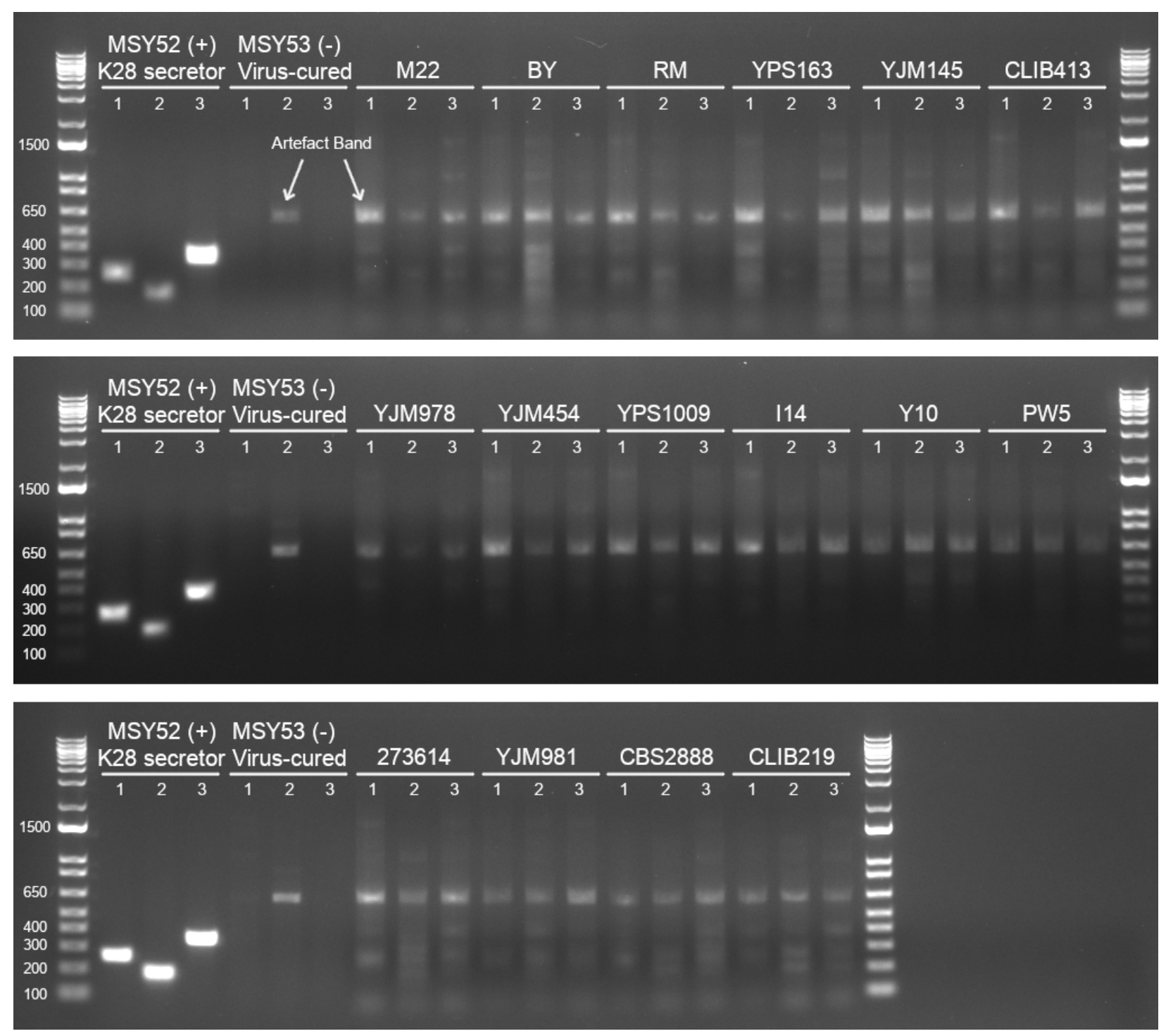

\section{Figure S3. RT-PCR-based Virus Typing.}

Three separate PCRs were performed on cDNA prepared from the 16-isolate panel and two control strains. Each PCR was designed to amplify a part of the M28 virus's genome sequence (18). Primer sequences are provided in Table S8 (PCR 1: expected size of 253 bp; PCR 2: expected size of $180 \mathrm{bp}$; PCR 3: expected size of $350 \mathrm{bp}$ ). Ladder is $1 \mathrm{~kb}$ Plus (Invitrogen). Shown gel is representative of $n=3$ biological replicates, derived from three colonies of each strain. 


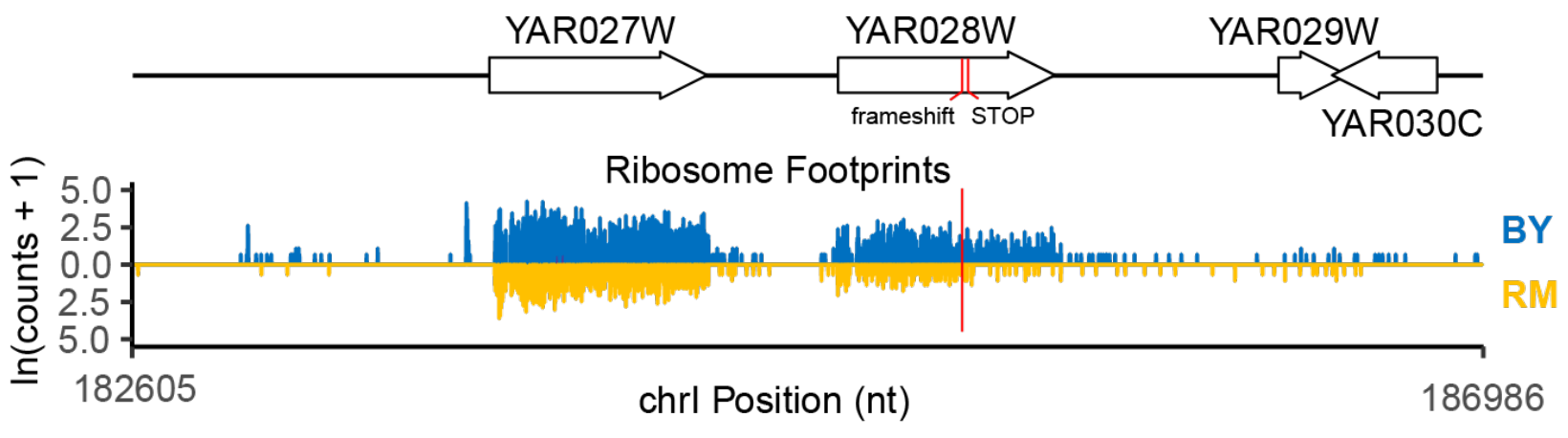

Figure S4. Ribosome profiling of BY and RM strains near the YAR027W (UIP3) and YAR028W (KTD1) genes.

Log-transformed counts of ribosome footprints, as determined by Albert, et al. (27), are shown in a window of chromosome I encompassing UIP3 (YAR027W) and KTD1 (YAR028W).

Footprints are plotted in blue for BY and gold for RM. The positions of deleterious mutations in RM are marked with a vertical red line. 


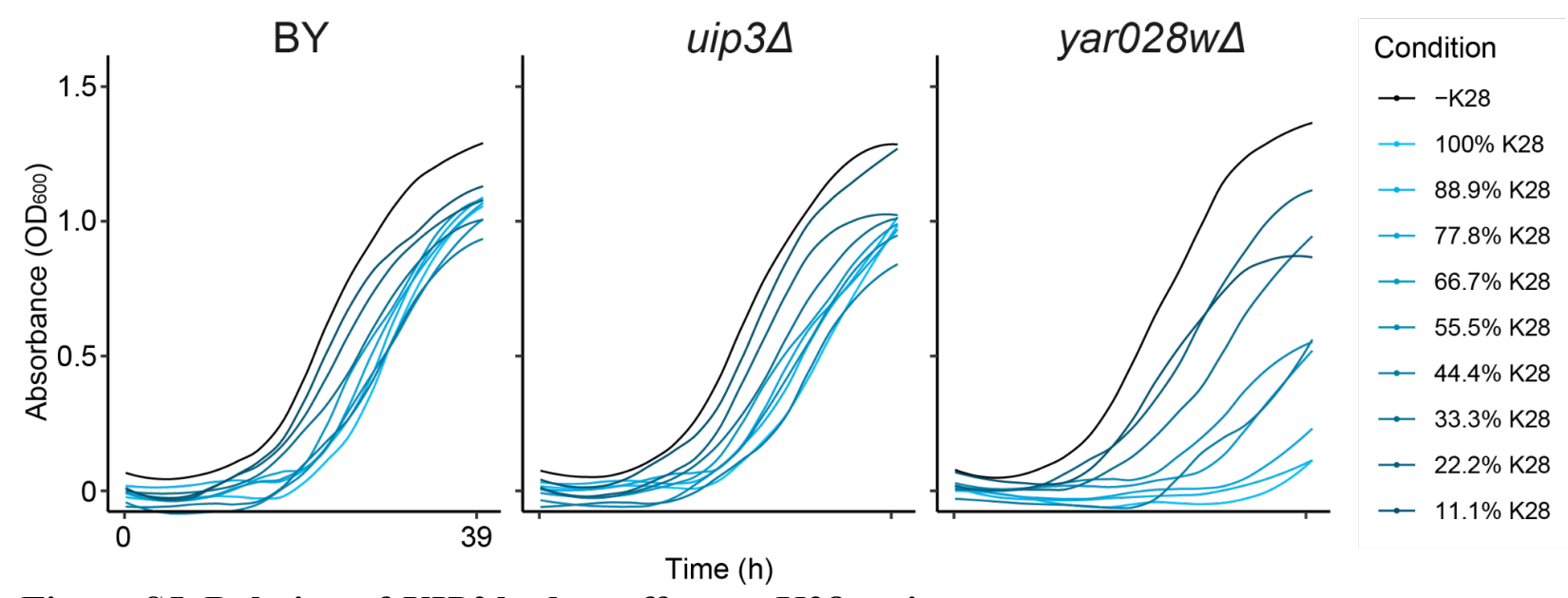

Figure S5. Deletion of UIP3 had no effect on K28 resistance.

BY, BY uip3 4 , and BY yar028w 4 (ktd14) were grown in media containing different concentrations of K28, generated by mixing the supernatants of K28-producing (MSY52) and virus-free (MSY53) yeast strains. Legend indicates the percentage of toxic supernatant (X\%) diluted in non-toxic supernatant $(100 \%-\mathrm{X} \%)$. 
A
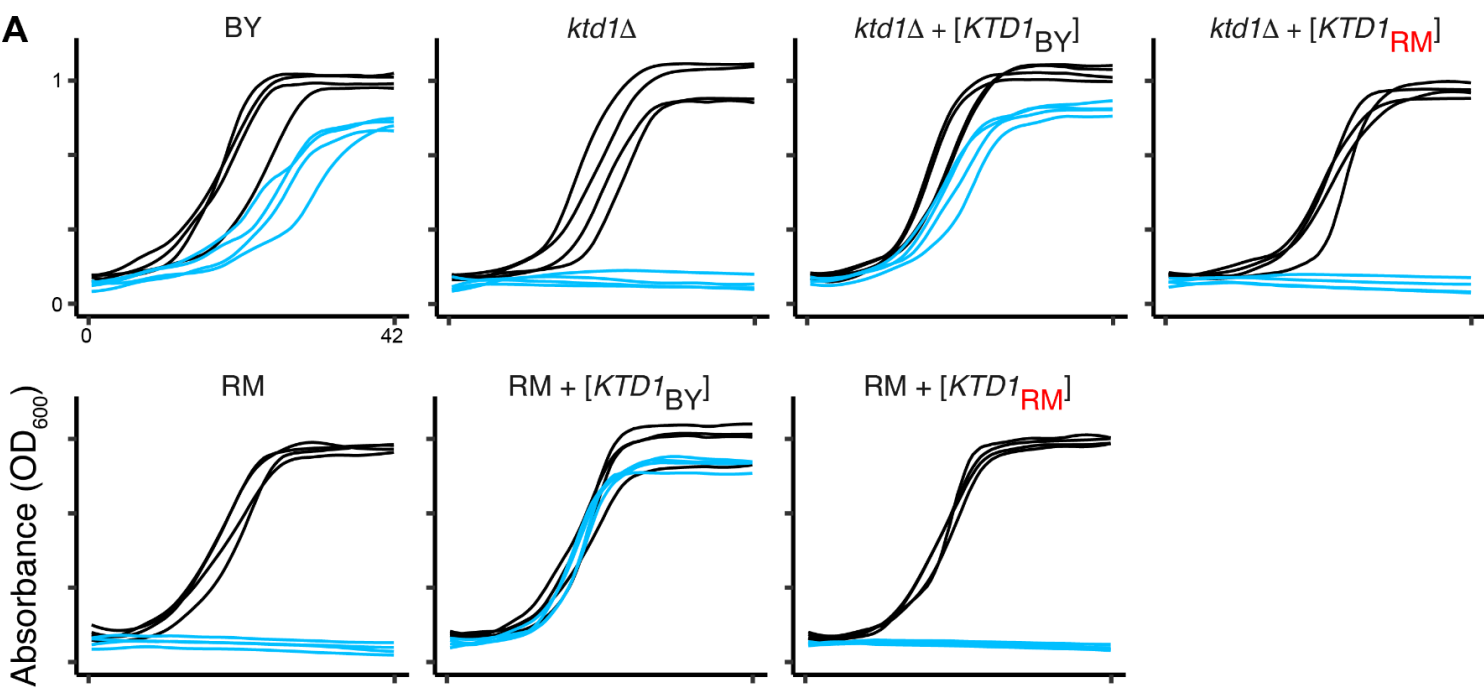

Time (h)

B

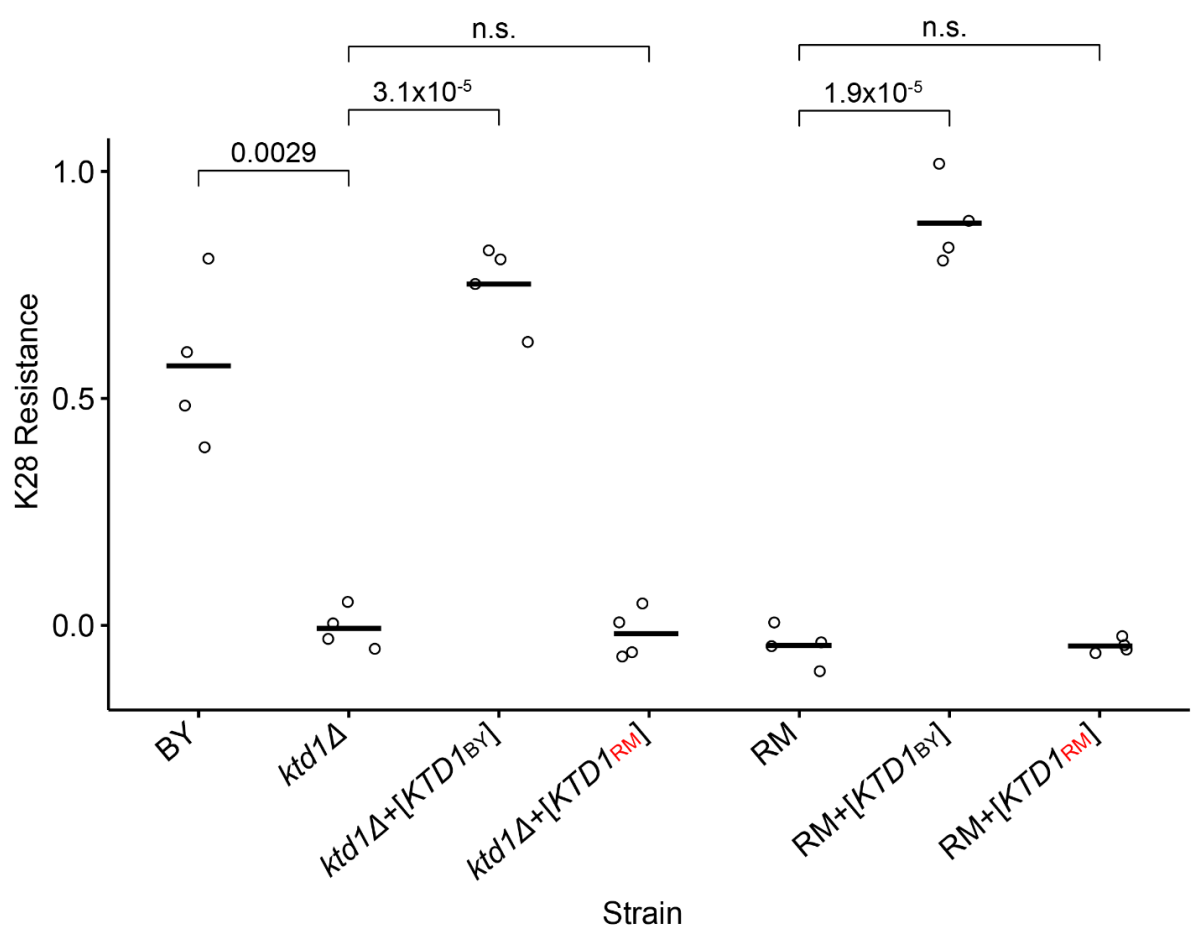

Figure S6. Expression of the RM allele of $K T D 1$ did not protect against K28.

(A) Growth curves of BY, RM, and BY ktd1 1 are shown, expressing either the BY or RM allele of $K T D 1$, or empty vector. Blue curves correspond to growth in media containing K28; black curves correspond to growth in media without $\mathrm{K} 28$, with $n=4$ biological replicates per strain. A subset of these curves are also shown in figure 2D and E. (B) From the growth curves shown in part A, K28 resistance was quantified as $\mathrm{AUC}_{+\mathrm{K} 28} / \mathrm{AUC}_{-\mathrm{K} 28}$. Welch's two-sample $t$-tests were used to compare levels of $\mathrm{K} 28$ resistance between strains. 
A Growth of RM in K28-containing supernatant after the supernatant was adsorbed to...
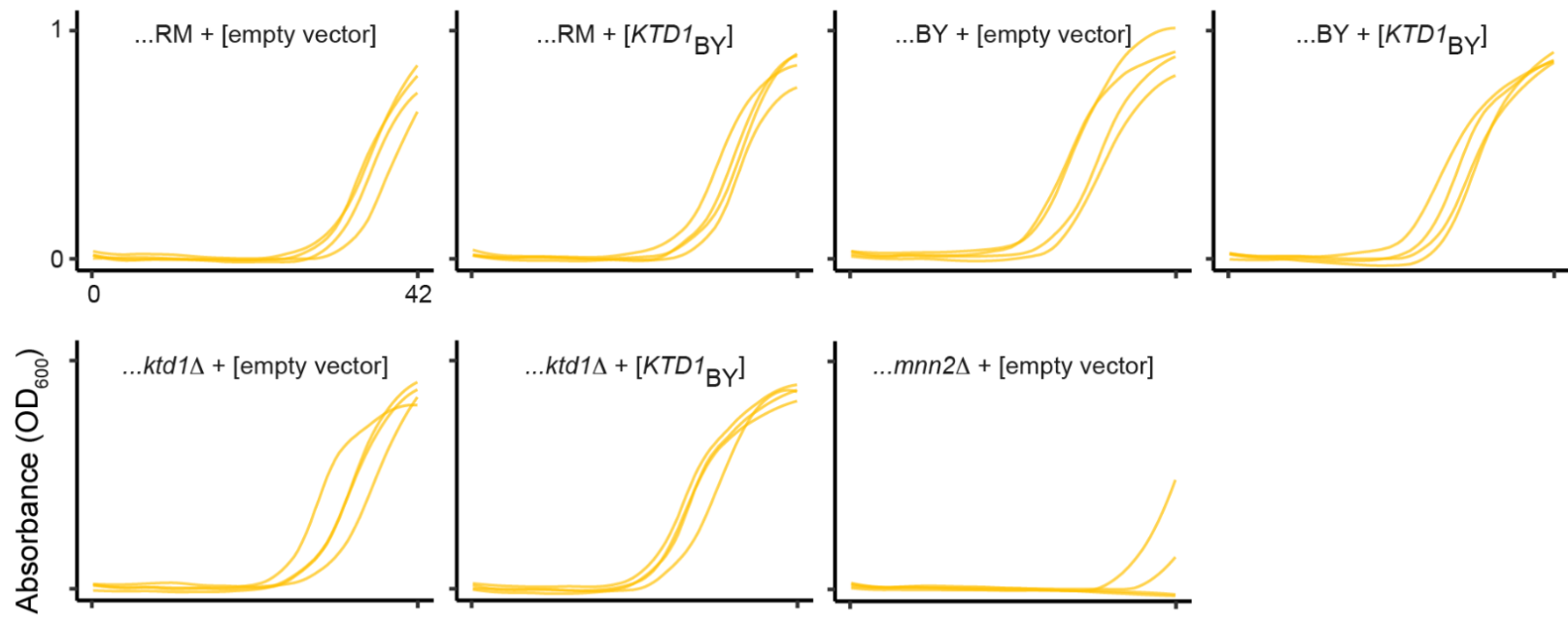

Control growth of RM:
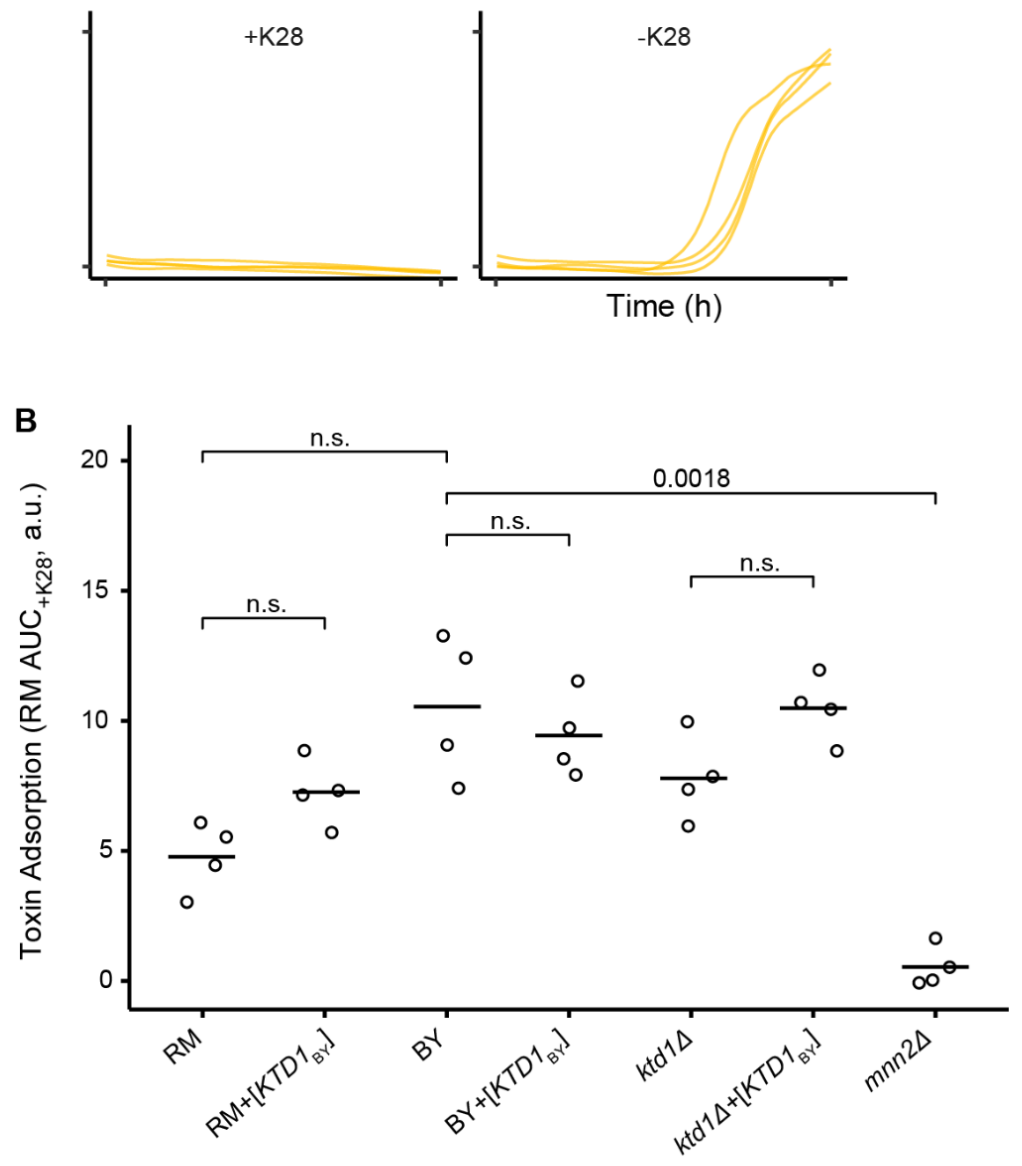

\section{Adsorbing Strain}

Figure S7. Effect of Ktd1p on adsorption of K28 to the cell surface

(A) Supernatant from K28-secreting MSY52 was applied to cells of the genotypes shown ( $n=4$ biological replicates) for 15 minutes, after which the supernatant was filter-sterilized to remove the cells and any K28 adsorbed onto their surface. The level of remaining K28 toxin was 
determined by the ability of the K28-sensitive RM strain to grow in the supernatant. As controls, the growth of RM in supernatant of MSY52 (with toxin) and MSY53 (toxin-free) without an adsorption step is shown. (B) Quantification of the inhibition of RM's growth by non-adsorbed $\mathrm{K} 28$, measured as $\mathrm{AUC}_{+\mathrm{K} 28}$ (vertical axis) from the growth curves in part A. Higher values indicate more toxin was adsorbed, hence the growth of RM was less inhibited. Statistical analyses were performed using Welch's two-sample one-tailed $t$-tests, with the alternative hypothesis that $K T D 1_{\mathrm{BY}}$ leads to decreased toxin adsorption. 
bioRxiv preprint doi: https://doi.org/10.1101/2021.10.25.465803; this version posted October 25, 2021. The copyright holder for this preprint (which was not certified by peer review) is the author/funder. This article is a US Government work. It is not subject to copyright under 17 USC 105 and is also made available for use under a CCO license.

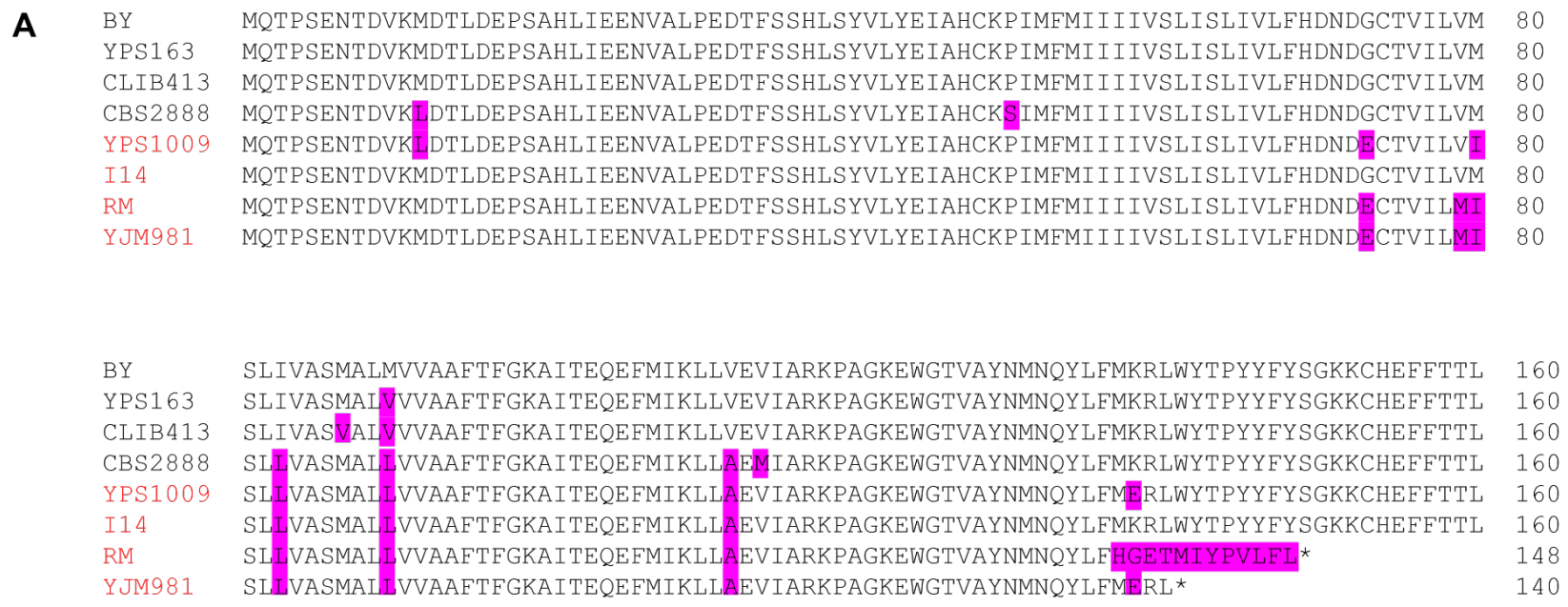

BY IKEVNSGSHSDSSSNSAEDTQSPVSAGKTSNGLNNFYSIRSDPILMAYVLKATQIEKEAQSEYWRKQYPDADLP* 234 YPS163 IKEVNSGSHSDSSSNSAEDTQSPVSAGKTSNGLNNEDSIRSDPILMAYVLKATQIEKEAQSEYWRKQYPDADLP* 234 CLIB413 IKEVNSGSHSDSSSNSAEDTQSPVSAGKTSNGLNNEDSIRSDPILMAYVLKATQIEKEAQSEYWRKQYPDADLP* 234 CBS2888 IKEVNSGSHSDSSSNSAEDTQSPVSAGKTSNGLNNEDSIRSDPILMAYVLKATQIEKEAQSEYWRKQYPDADLP* 234 YPS1009 IKGVNSGSHSDSSSNIAEDTQSPVSAGKTSNGPNNEDSIRSDPILMAYVLKATQIEKEARSEYWRKQYPGADLP* 234 I14 IKEVNSGSHSDSSSNSAENTQSPVSAGKTSNGLNNEDSIRSDPILMAYVLKATQIEKEAQSEYWRKQYPDADLP* 234 RM Y JM981

B

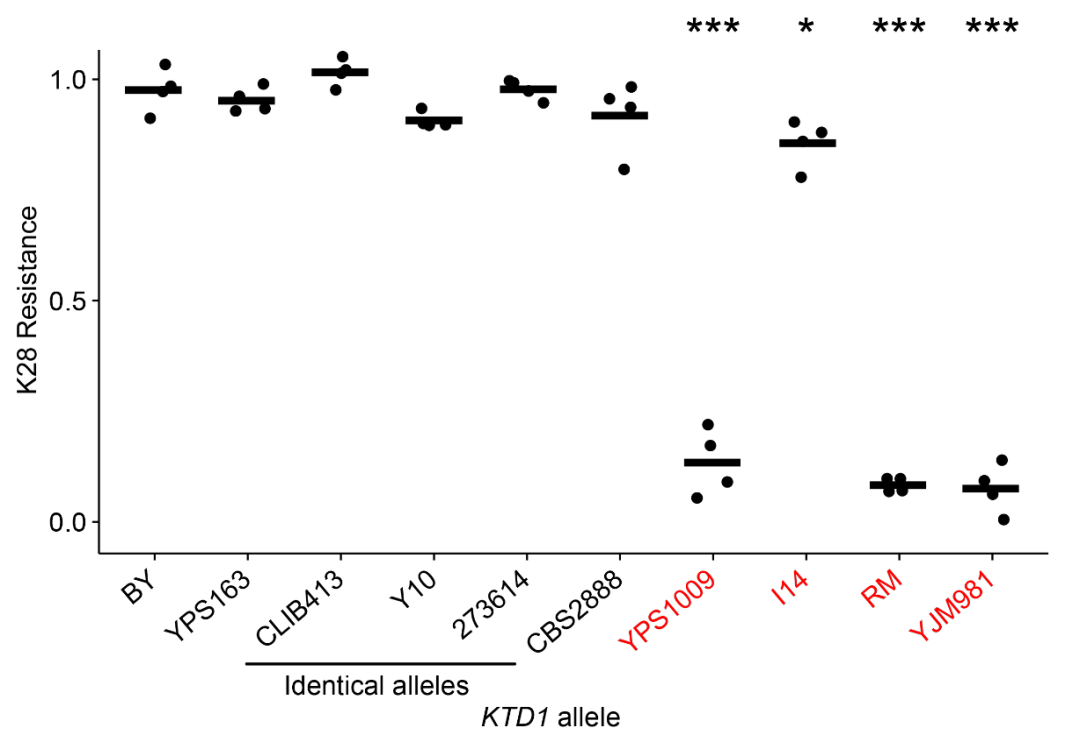

Figure S8. KTD1 alleles from the 16-isolate panel.

Strain names are colored according to K28 resistance as determined in Fig. 1B (black, resistant; red, sensitive). (A) Amino acids that differ from the reference sequence (BY) are highlighted in magenta. Strains Y10 and 273614 had KTD1 alleles identical to CLIB413 and are not shown here. Sequences were determined by Illumina Moleculo sequencing performed in Bloom, et al. (17). (B) From the growth curves shown in figure 3B of BY ktd1 1 expressing various KTD1 alleles, K28 resistance was quantified as $\mathrm{AUC}_{+\mathrm{K} 28} / \mathrm{AUC}_{-\mathrm{K} 28}$ with $n=4$ biological replicates per strain. ANOVA followed by Tukey's HSD identified the six alleles from resistant strains and 
bioRxiv preprint doi: https://doi.org/10.1101/2021.1025.465803; this version posted October 25,2021 . The copyright holder for this preprint

(which was not certified by peer review) is the author/funder. This article is a US Government work. It is not subject to copyright under 17 USC 105 and is also made available for use under a CCO license.

$K T D 1_{\mathrm{I} 14}$ as conferring more resistance than $K T D 1_{\mathrm{YPS} 1009}, K T D 1_{\mathrm{RM}}$, and $K T D 1_{\mathrm{YJM} 981}(* * * P<$ 0.001 for all 21 pairwise comparisons). $K T D 1_{\mathrm{I} 14}$ conferred less resistance than $K T D 1_{\mathrm{BY}}\left({ }^{*} P<\right.$ $0.05), K_{T D 1_{273614}}(P<0.05)$, and $K T D 1_{\mathrm{CLIB} 413}(P<0.01)$ at more moderate thresholds for statistical significance, but was not significantly different from the alleles from other resistant strains. 
bioRxiv preprint doi: https://doi.org/10.1101/2021.10.25.465803; this version posted October 25, 2021. The copyright holder for this preprint (which was not certified by peer review) is the author/funder. This article is a US Government work. It is not subject to copyright under 17 USC 105 and is also made available for use under a CCO license.

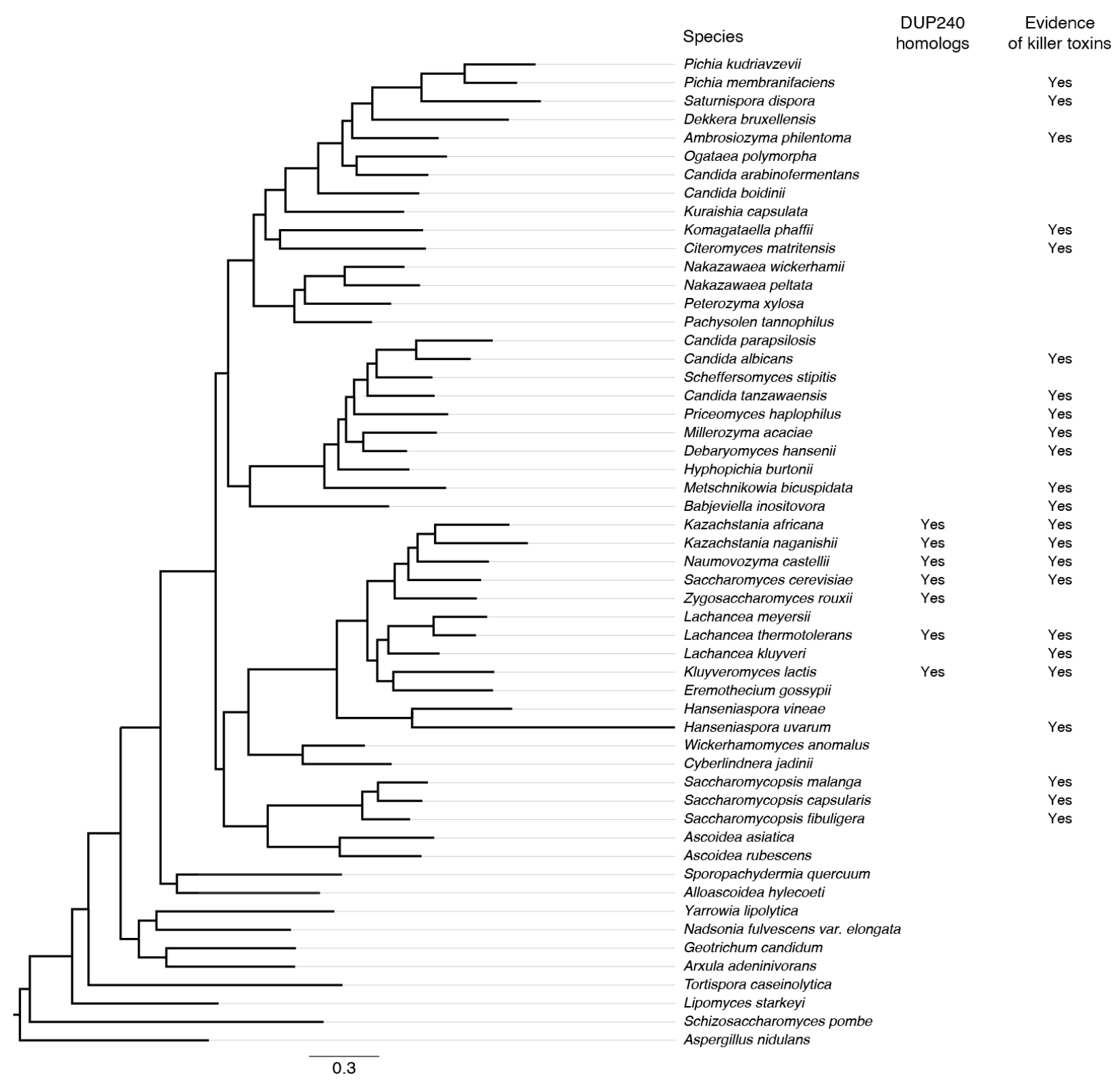

Figure S9. Species distribution of homologs of DUP240 genes.

Homologs of DUP240 genes were found by performing tblastn searches against each genome shown on the tree, with the Ktdlp protein sequence as query. All negative hits were negative both with the default tblastn search parameters and with the tblastn Expect threshold relaxed to 0.5 . Evidence of killer toxins is largely as reported by Krassowski, et al. (52), with the exception of $P$. membranifaciens, $K$. africana, $N$. castellii, and $H$. uvarum $(20,53,54)$. Phylogenetic species tree modified with permission from Krassowski, et al. 


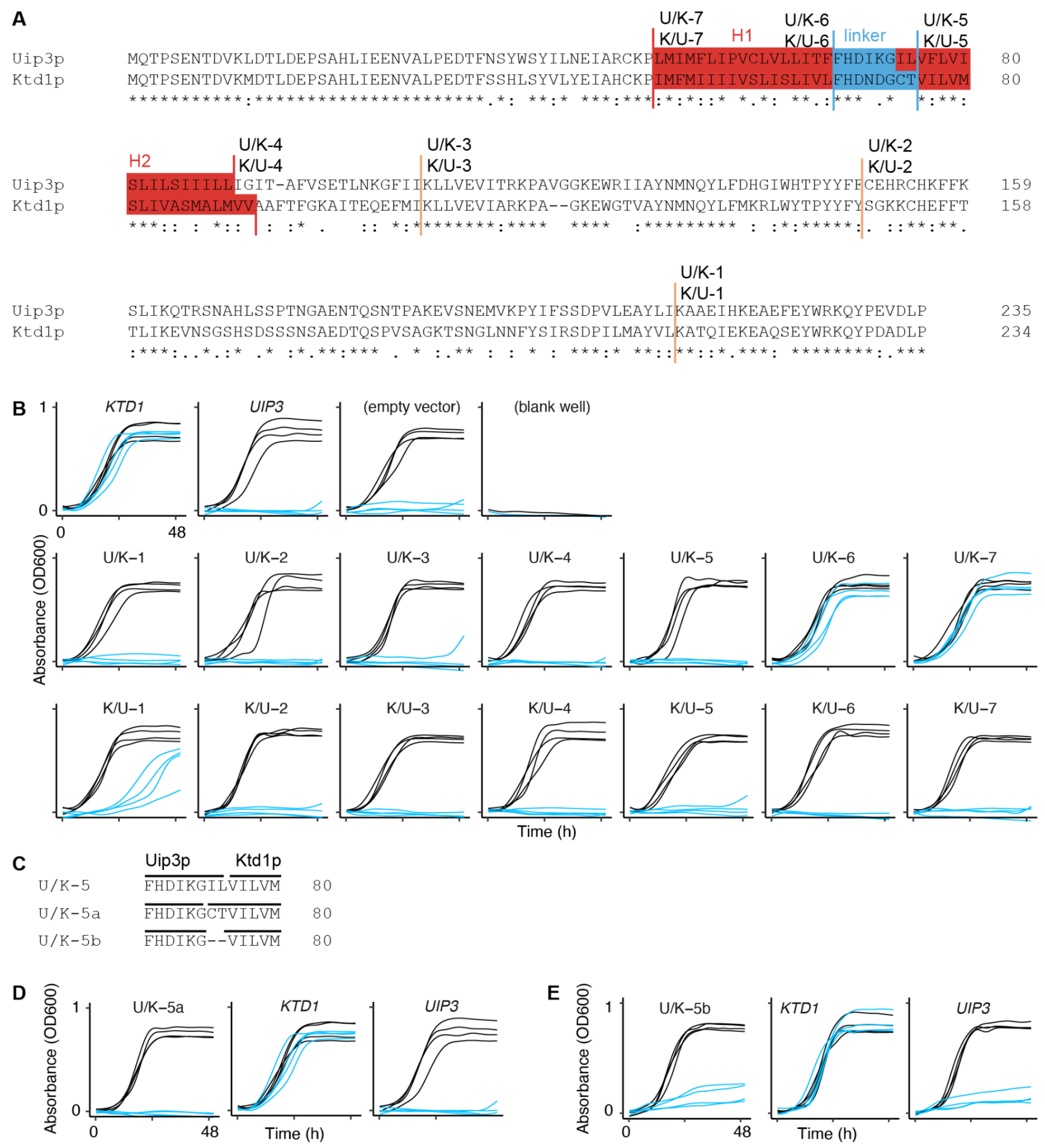

Figure S10. Analysis of chimeras between Uip3p and Ktd1p.

(A) Alignment of Ktd1p and Uip3p. Chimera transition points are marked with vertical lines and the names of the chimeras transitioning there. The transmembrane helices $\mathrm{H} 1$ and $\mathrm{H} 2$ are colored in red and the linker between them is colored in blue. We used the positions of the transmembrane domains as defined in Poirey et al. (25). (B) The K28 resistance shown in figure 4A was quantified as $\mathrm{AUC}_{+\mathrm{K} 28} / \mathrm{AUC}_{-\mathrm{K} 28}$ calculated from the growth curves shown here of BY $k t d 1 \Delta$ expressing the labeled chimeras, with $n=4$ biological replicates per strain. Blue growth curves are of strains grown in media containing K28, and black growth curves are of strains grown in media lacking K28. (C) We additionally tested two alternative Uip3p-Ktd1p chimera 
transition points near the transition point used in $\mathrm{U} / \mathrm{K}-5$. U/K-5a transitions at a conserved glycine within the interhelix linker, and U/K-5b transitions from the end of Uip3p's linker to the start of Ktd1p's H2 transmembrane domain. (D) Growth curves of BY ktd1 1 expressing U/K-5a in media with and without K28. BY ktd1A expressing either KTD1 or UIP3 are shown for comparison. (E) Growth curves of BY ktdl $1 \Delta$ expressing U/K-5b in media with and without K28. BY ktd1 14 expressing either KTD1 or UIP3 are shown for comparison. In D and E, U/K-5a and $\mathrm{U} / \mathrm{K}-5 \mathrm{~b}$ conferred significantly less resistance than KTDl $(P<0.001$ by Welch's two-sample $t$ test) and were not distinguishable from UIP3. U/K-5a was tested in the same experiment as the chimeras shown in B; U/K-5b was tested separately. 
DFP 22 DFP 14 DFP 24

KTD1

UIP 3

DFP 13

DFP 17

DFP 16

DFP2 3

DFP 25

DFP 21

DFP 18

DFP 15

DFP 12

PRM9

DFP 20

MST2 8

DFP 11

Unique

Pos. sel.

DFP 22

DFP1 4

DFP2 4

KTD1

UIP 3

DFP 13

DFP 17

DFP 16

DFP2 3

DFP 25

DFP 21

DFP 18

DFP 15

DFP 12

PRM9

DFP 20

MST 28

DFP 11

Unique

Pos. sel.

DFP2 2

DFP 14

DFP2 4

KTD 1

UIP3

DFP 13

DFP1 7

DFP 16

DFP 23

DFP 25

DFP2 1

DFP 18

DFP 15

DFP 12

PRM9

DFP 20

MST 28

DFP 11

Unique Pos. sel.

H1

MHISLESTDTKLDTSNEPSAQLIEENVALPKDIFRSYLSYWIYEAAHCTPVMFLSLVIGVLISI I ILFHDNKNCVGVSVGFLVIFF IIFG MQASSENANTKLDTLSEPSAHL IEENVALPEDTFRSYLSYLLYEMAHYKP IMVLLSVIATLGVLITLFHNNDTCSI IFGISLF ISSLVLL MQCF SGYRNGKLRTLNEAGT HL IEENVVLPKE IF SSYWNYLL YEMAHCKP IMVLLSVITTLGVLITLFHNNDACS I IFGISLF ISSLVLL MQTP SENTDVKMDTLDEPSAHL IEENVALPEDTF SSHLSYVLYE IAHCKP IMFMI I I IVSLI SL IVLFHDNDGCTVILVMSLIVASMALM MOTPSENTDVKLDTLDEPSAHL IEENVALPEDTFNSYWSYILNE IARCKPLMIMFL I PVCLVLLITFFHDIKGILVFLVISLILSI I ILI MQTPSETADVKLDVLNEPSAHL IEENVALPEDTFRSYWSYLLYEMAHYKPI IFMTPITASLILS IVLFHDIPGILTFSVISLLLSI I ILL MOTP SENTDVKLDTLDEP SAHL IEENVALPKE IF SSYWSYVLYEMARYKLIVIVLLLNVCLVLLFLFFHDGVLTISFYSLSLIFCLPMLG MQAPSENTDVKLDTSNEPSAHLIEENVALPKE IFSSYWSYVLYEMARYKLIVIVLLLNVCLVLLFLFFHDSVVS ILFYVFSLLFSLPMLG MQAP SENTDVKLDTSNEPSAHL IEENVALPEE IFHSYLSY ILYEMVHY IP IVI I FLLNVCLVLLFLFFHDGPGT ILFYVF SLFCSLPMLV MOAPSENTDVKLDTLNEPSAHLIEENVALPKE IFSSYWSYVPYEMARYKLIVIVLLLNVCLVLLFLFFHDGVLTISFYLLSLIFCLPMLG MOAPSENTDTKLDTSNEPSAHLIEENVALPEDTFRSYLSYWI YDILHYKPVVITFLLNTCLVLLFLFFHDSVVS ILFYVSSLLF SLPMLY MQAPSENTDTKLDTSNEPSAHL IEENVALPEDTFNSYWSYVLYEMTRYKLIVIVLLLNVCLVLLFLFFHYSFVSTFFYVFSLLLSLPMLY MQTPSESTDTKLDTSNEP SAHL IEENVALPEE IFHSYF SYLLYEMAHCKPVMITFLLNTCLVLLFLFFHDSPST ILFY IYSLLIFVPMLG MOASSENANTKLDTLSEPSAHL IEENVALPED IF SSYWSYLFHEVLHNIVIMIMFSVNVCLTLLFLFF PHKKVH-FFYVLSWVVSGF ILL MOTSSESTDAKS DFLDEPSAYL IEKNVALPKDIFGSYLSYWI YEVTRHKAAVILLVLIVTSILLLVFFYNTEFCVAFEILLF SFCF PGTC MQTPPESTDVKLDTLNEPSAHS IEENVALPKDIFRSYWSYWVYNMLHYEPIMILGVLLVSSVSSIILLHNNTACVVVSALLAFLSLVALL MQTPPESTDVKLDTLNEPSAHLIEKNVALPKDIFRSYLSYWIYEIARYTPVMILSLVIGVLVLLI IFFNDNEACVFNSA IFAFTSLVGLI MEAPSEITDSKSDTSKGLDAQL IEKNVALPKDIFRSYLSYCIYDMLRYKP IMVP GAVSVGSVLS IVFLHDNIACVVISAVLAGISLFA-L 134332532513232423323211211211222151232155334424444336663645243334224468855845683466466536 **

$* * * * * *$

CVLGGIFGIP ICDRDFKI KLLGETIARRPA--GREWRTVAYNMNQYLFDEGLWYTPYYFYCGRKCQYFFNNLVK IEGPNTHLSSPTNDEE MALIAM-SVRISDRDFI I KLLLEVITRKPA--GKGWRTVAYNMNQYLFHEGLWYTPYYFYCGRKCQYFFNSLIETKKPNTESGSPTEDEE VVVLSTFADPITEQDFVIKLSVEVIARKPV--EKAWGTVAYNMNQYLFMEGLWHTPYYFYSGKKCHGFFTTLTKKVNSSSYSDSSSNSVE VVAAFTFGKAITEQEFMIKLLVEVIARKPA--GKEWGTVAYNMNQYLFMKRLWYTPYYFYSGKKCHEFFTTLIKEVNSGSHSDSSSNSAE I-GITAFVSETLNKGF I I KLLVEVITRKPAVGGKEWR I IAYNMNQYLFDHGIWHTPYYFFCE HRCHKFFKSLIKQTRSNAHLSSPTNGAE I-SIGTFAAGTWDKDSKVKLLLEVIARKPAVGGKEWR I IARNMNQYLFDHGQWF TPYYFLCEHRCHEFFKSLIEQERSNTHTSPPTNGAE ASVGEF-TKP IRNODFE INLLVEVIKRKPAVRGKEWRTITYNMNOYLFDHGLWNTPYRFYDEEDCHRYFLRLIEGKTFKKOGDPPTSNVT ASVGEF IMKP IONQDFE I NLLVEV I KRKPAVKGKEWRTITYNMNQYLFDHRLWNTPYCFYDDEDCHRYFLRLIE GKTFKKOGDP PT SNVT ASVGEF IMKP IRNQDFK I NLLVEVIKRKPAVKGKEWRTITYNMNQYLFDHRLWNTPYCFYDDEDCHHYFLRLIEGKTFKKQGDSPTSNVT ASVGEF-TKP IRNQDFE INLLVEVIKRKPAVRGKEWRTIAYNMNQYLFDHRLWDTPYYFYDDEDCHSYFLSLIEGRTFKKQEESSASNVT YSYEEF-TIPIONLDFE INLLVEVVKRKPAVKGREWRTIAYNMNOYLFDHRLWDTPYYFYDDEDCHSYFLSLIEGRTFKKOEESSASNVT YSYEEF-TIPIQNQDFEAELLVEVIKRKPAVRGKEWRTITYNMNQYLLGHGLWNTPYYFYGDEQCYVYFLSLIAGVTPKKQTTASIDDIA AF IKRS-RAPIQNQDFEAELLVEVIKRKPAVRGKEWRTITYNMNQYLLGHGLWNTPYYFYGDEQCYVYFLSLIAGVTPKKQTTASIDDIA VSSIVF-AKP INDODFKINLLIEVIARKPAVKGKEWRTITYNMNOYLFDDDLWNTPYYFYRDKDCRRYFLRLVEGRTFKKOEESSTSNVT MVVIAF-SEP IGDREFKVKLLMEI ITRKPAVKGKEWRTITYKMNQYLFDHGLWDTPYYFYRDEDCHRYFLSLIKGRTFKKQKESSASNVK VMLGDGYPRLVNRRNFETELLVDVITRKPAVE GKEWRI ITYNMNQYLFNHGQWH TPYCFYNDEDCYRYFLRLVEGVTPKKQTATSIG--IILSDGNPKLVSRRNFRTELLVDVITRKPAVEGKEWRI ITYNMNQYLFNHGQWHTPYYFYSDEECYRYFLRLVEGVTPKKQTATSIG--MIVGDGYLKPVSRRDFETELLVEVITRKPAVEGKEWK I ITYKMNQYLFNHGQWH TPYYFYGDEDCYRYFLSLIEGI TAKKQTPTSIGYST 667797498639444264312523231212142231322222111112543315111313634514821441336654444674245554 *

NTQPD----ASE IEVLNVVGRFF IHSPDPILEAYLIKAAEINKEAEFEYWRKQY PEVD-LP---NTQPDTQPDTSPNEALDEVLRYYFCI PDPNLEAYFVKAAEADQEAQHEYWRKQY PEAA-LP--DTQSP----VSAEKTTNGPNKFDS IRSDPI LMTY ISKAIEVE KEAQREYWRTQY PDAD-LP---DTQSP----VSAGKTSNGLNNFYS IRSDPI LMAYVLKATQIE KEAQSEYWRKQY PDAD-LP---NTQSN----TPAKEVSNEMVKPY IFS SDPVLEAYLIKAAE IHKEAEFEYWRKQY PEVD-LP---NT--------PANKVSNDVEKS YMF S SDPVLEAYFVKAAE IDKEAQFEYWRKQY PELD-LP---DAQSN----DETAGTPNEAAESFTFHSGPNYQKYLSKAAEIEQQSQDNYWQGRH PDIDALP---DAQSN----DETAGTPNEAAESFTFHSGPNYQKYLSKAAE IEQQSQDNYWQGRH PDINALP---DAQSN----EATTSPPIGATESFTFHSGPNYQKYLSKAAE IEQQSQDNYWQGRH PDIDALLKKTE DAQSN----DETAGTPNEAIEF FTFHSGPNYQKYLSKAAEIEQQAQNNYWKERY PEMNAVL---DAQSN----DETAGTPNEAIEFFTFHSGPNYQKYLSKAAE IEQQAQNNYWQGRHPDIDALLKKTE DAQSN----VPTTVTPGEDIEPASPSSAPNYRNFLLKAAE IEQQAQNNYWKERY PEMNAVL---DAQSN----VPTTVTPGEDIEPAS PSSAPNYRNFLLKAAE IEQQAQNNYWKERY PEMNAVL---GIQSD----EATTGTPMEATKSFTFSVGPNFTKLLTKAAEVEQQAQNNYWQERY PEINAIV---DAQSN----DETAGTPNEAAES SSF SAGPNF I KLLTKAAE IEQQFOKEYWRQEY PGVDEFF--- $----\mathrm{N}----$ SPVTAKPEDAIES ASPS SRLNYRNFLLKAAE IERQAQENYWRRRH PNIDALLKKTE $----N----S$ PVTAKPEDAIESASP S SRLNYRNFLLKAAE IERQAQENYWRRRH PNIDALLKKTE GTQLN----SSVTAESEDAIESVPPSPGQNYQNFLLKAAE IDQQAQENYWRRRH PNIDALLKKTE 33133111164576646468446654443336434511323432328211363214532441111

\section{Figure S11. Regions of divergence between DUP240 proteins.}

In our 16-isolate panel we found 25 DUP240 genes; of these, the 18 full-length DUP240 proteins most similar to Ktd1p are shown in this alignment. DUP240 genes with no previous standard name were named DFP ( $\underline{D}$ UP240 family protein). The locations of transmembrane domains TM1 and TM2 were determined by PHOBIUS (31). Along the bottom of the alignment we show the number of unique amino acids represented at each position in the alignment ("Unique") and the sites identified as experiencing positive selection (“Pos. sel.”); see figure 4B. 


\begin{tabular}{|l|l|}
\multicolumn{1}{c}{ Strain Name } & \multicolumn{1}{c|}{ Environmental / Geographical Origin } \\
\hline RM11-1a (MATalpha) & Vineyard / Italy \\
\hline M22 (MATalpha) & Vagina / Italy \\
\hline YJM981 (MATalpha) & Vineyard soil / Italy \\
\hline I14_1b (MATa) & Fermenting rice / China \\
\hline CLIB413_1b (MATa) & NA / NA \\
\hline 273614N (MATa) & Raphia palm wine / NA \\
\hline PW5_b (MATalpha) & (Prototrophic version of a common lab strain) \\
\hline BY (MATa) & Human, clinical / NA \\
\hline YJM454 (MATa) & AIDS patient / NA \\
\hline YJM145 (MATalpha) & Coconut / Philippines \\
\hline Y10 (MATalpha) & Wine / Russia \\
\hline CLIB219 (MATalpha) & Exudate, Quercus sp. (oak) / NA \\
\hline YPS1009 (MATalpha) & Soil / South Africa \\
\hline CBS2888 (MATa) & Soil beneath Quercus rubra (oak) / PA, USA \\
\hline YPS163 (MATa) & NA / NA \\
\hline YJM978 (MATalpha) & \\
\hline
\end{tabular}

Table S1. Origin of the $S$. cerevisiae strains in the 16-isolate panel surveyed in this study Strains and their origin information from Bloom, et al., 2019 and Peter, et al., $2018(17,30)$. NA $=$ information not available. 


QTL
\begin{tabular}{|c|c|c|c|c|c|} 
& Chr & Peak Marker Position & Left Marker & Right Marker & LOD Score \\
\hline 1 & I & 184648 & 180646 & 184686 & 49.72978 \\
\hline 2 & XII & 745464 & 250697 & 967302 & 4.11199 \\
\hline 3 & XIV & 468488 & 467028 & 485549 & 11.36227 \\
\hline
\end{tabular}

Table S2. QTLs identified from linkage mapping of K28 resistance variation in a BY $\times$ RM cross.

912 segregants from a BY $\times$ RM cross were phenotyped for resistance to K28 killer toxin, measured as $\mathrm{AUC}_{+\mathrm{K} 28} / \mathrm{AUC}_{-\mathrm{K} 28}$. The genotypes at 28,220 biallelic markers spanning the genome were associated with $\mathrm{K} 28$ resistance, generating the LOD plot in figure 2B. We identified three QTLs that passed a 5\% family-wise error rate (FWER) LOD threshold of 3.55, computed from 1000 iterations of randomly assigning phenotypes to segregants and calculating the top LOD score. The left and right markers denote $95 \%$ confidence intervals for the position of the LOD peak marker. These were determined from the positions of peak LOD scores on chromosomes I, XII, and XIV from 1000 bootstrap samplings. 
Gene ID Gene name What is known

\begin{tabular}{|c|l|l|c|}
\hline YAR023C & DFP1 & Premature stop in reference allele & $(55)$ \\
\hline YAR027W & UIP3 & Interacts with Ulp1p & (56) \\
\hline YAR028W & KTD1 & Protects against K28 & $(55)$ \\
\hline YAR029W & DFP2 & Pseudogene & $(35)$ \\
\hline YAR031W & PRM9 & Interacts with COPII & $(35)$ \\
\hline YAR033W & $M S T 28$ & Interacts with COPI & $(35)$ \\
\hline YCR007C & DFP3 & & \\
\hline YGL051W & $M S T 27$ & $\begin{array}{l}\text { Interacts with COPI; multicopy suppressor } \\
\text { of COPI mutants }\end{array}$ & \\
\hline YGL053W & PRM8 & Interacts with COPII & \\
\hline YHL044W & DFP4 & & \\
\hline
\end{tabular}

\section{Table S3. DUP240 genes in the yeast reference genome.}

We have named the four remaining unnamed DUP240 genes in the $S$. cerevisiae reference genome as DFP ( $\underline{D U P 240}$ family proteins). 


\begin{tabular}{|c|c|c|c|c|c|c|c|c|c|c|c|c|c|c|c|c|c|c|c|c|c|c|c|}
\hline Strain & \multicolumn{8}{|c|}{ DUP240s in the reference genome } & \multicolumn{15}{|c|}{ DUP240s not in the reference genome } \\
\hline & & & & & & & & & & & & & & & & & & & & & & & \\
\hline 1 & 1 & 0 & 0 & 1 & 0 & 1 & 1 & 1 & 0 & 0 & 0 & 0 & 0 & 0 & 0 & 0 & 0 & 0 & 0 & 0 & 0 & 0 & 0 \\
\hline 2 & 0 & 0 & 0 & 0 & 0 & 1 & 1 & 0 & 1 & 1 & 1 & 1 & 0 & 0 & 0 & 0 & 0 & 0 & 0 & 0 & 0 & 0 & 0 \\
\hline 3 & 1 & 0 & 1 & 1 & 0 & 1 & 1 & 1 & 0 & 0 & 0 & 0 & 0 & 0 & 0 & 0 & 0 & 0 & 0 & 0 & 0 & 0 & 0 \\
\hline 4 & 1 & 1 & 1 & 1 & 1 & 1 & 1 & 1 & 0 & 0 & 0 & 0 & 0 & 0 & 1 & 1 & 1 & 0 & 0 & 1 & 1 & 0 & 0 \\
\hline 5 & 1 & 1 & 0 & 0 & 0 & 1 & 1 & 1 & 0 & 0 & 0 & 0 & 0 & 0 & 0 & 0 & 0 & 1 & 0 & 0 & 0 & 0 & 0 \\
\hline 6 & 1 & 1 & 1 & 1 & 0 & 1 & 1 & 1 & 0 & 0 & 0 & 0 & 0 & 0 & 0 & 0 & 0 & 0 & 0 & 0 & 0 & 0 & 0 \\
\hline 7 & 0 & 0 & 0 & 0 & 0 & 1 & 0 & 0 & 1 & 1 & 1 & 1 & 0 & 0 & 0 & 0 & 0 & 0 & 0 & 0 & 0 & 1 & 0 \\
\hline 8 & 1 & 1 & 1 & 2 & 1 & 1 & 1 & 0 & 0 & 0 & 0 & 0 & 0 & 0 & 0 & 0 & 0 & 0 & 0 & 0 & 0 & 0 & 0 \\
\hline 9 & 0 & 0 & 0 & 0 & 0 & 1 & 1 & 0 & 1 & 1 & 1 & 1 & 0 & 0 & 0 & 0 & 0 & 0 & 0 & 0 & 1 & 0 & 0 \\
\hline 10 & 0 & 0 & 0 & 0 & 0 & 1 & 1 & 0 & 1 & 1 & 1 & 1 & 0 & 0 & 0 & 0 & 0 & 0 & 0 & 0 & 0 & 0 & 0 \\
\hline 11 & 1 & 1 & 0 & 1 & 0 & 1 & 0 & 1 & 0 & 0 & 0 & 0 & 0 & 0 & 0 & 0 & 0 & 0 & 0 & 0 & 1 & 0 & 0 \\
\hline 12 & 0 & 0 & 1 & 0 & 0 & 1 & 1 & 1 & 0 & 0 & 0 & 0 & 0 & 0 & 1 & 1 & 1 & 0 & 1 & 0 & 0 & 0 & 0 \\
\hline 13 & 1 & 1 & 0 & 2 & 0 & 1 & 1 & 1 & 0 & 0 & 0 & 0 & 0 & 0 & 0 & 0 & 0 & 0 & 0 & 0 & 0 & 0 & 0 \\
\hline 14 & 1 & 1 & 1 & 1 & 0 & 1 & 1 & 1 & 0 & 0 & 0 & 0 & 0 & 0 & 0 & 0 & 0 & 0 & 0 & 0 & 0 & 0 & 0 \\
\hline 15 & 0 & 1 & 0 & 1 & 0 & 1 & 1 & 1 & 0 & 0 & 0 & 0 & 0 & 0 & 0 & 0 & 0 & 0 & 0 & 1 & 1 & 0 & 1 \\
\hline 16 & 0 & 0 & 1 & 2 & 0 & 1 & 1 & 0 & 0 & 0 & 0 & 0 & 1 & 1 & 1 & 0 & 2 & 0 & 0 & 0 & 0 & 0 & 0 \\
\hline
\end{tabular}

Table S4. Presence and absence of DUP240 homologs in the genomes of strains in the 16isolate panel.

BLASTn was used to find all sequences homologous to any of the 10 DUP240 genes from the reference genome. Sequences with greater than $96 \%$ nucleotide identity were grouped as alleles; those with less than $96 \%$ nucleotide identity were called distinct genes. The sequences of 15 nonreference DUP240 genes have been deposited at SGD. 


\begin{tabular}{|c|c|c|c|c|}
\hline $\begin{array}{l}\text { Segment } \\
\text { (KTD1 } \\
\text { a.a.) }\end{array}$ & $\begin{array}{l}\text { Mean dN/dS } \\
\text { (Site model) }\end{array}$ & $\begin{array}{l}\begin{array}{c}\text { Likelihood-ratio } \\
\text { test statistic }\end{array} \\
2 *\left[\ln \left(\mathrm{L}_{M 8}\right)-\ln \left(\mathrm{L}_{M 7}\right)\right]\end{array}$ & $\begin{array}{c}p \text {-value of } \\
\text { chi }^{2} \text { test } \\
(\mathrm{df}=2)\end{array}$ & $\begin{array}{l}\text { KTD1 sites under positive selection } \\
\text { with } \operatorname{Pr}(\mathrm{dN} / \mathrm{dS}>1) \text { using BEB } \\
(*>0.95, * *>0.99)\end{array}$ \\
\hline 1-18 & $0.8200(\mathrm{M} 7)$ & 2.69 & 0.261 & N/A \\
\hline $19-36$ & 0.2911 (M7) & 0.90 & 0.637 & $\mathrm{~N} / \mathrm{A}$ \\
\hline $37-47$ & 0.4695 (M7) & 0.62 & 0.733 & $\mathrm{~N} / \mathrm{A}$ \\
\hline 48-89 & $2.0006(\mathrm{M} 8)$ & 40.28 & $1.795 \times 10^{-9}$ & $\begin{array}{c}\text { 55I, } 0.986(*) \\
\text { 56I, } 0.991\left(^{* *}\right) \\
72 \mathrm{D}, 1.000(* *) \\
73 \mathrm{G}, 0.988(*) \\
74 \mathrm{C}, 0.973(*) \\
76 \mathrm{~V}, 0.997(* *) \\
80 \mathrm{M}, 0.992(* *) \\
83 \mathrm{I}, 0.999(* *) \\
87 \mathrm{M}, 0.970(*)\end{array}$ \\
\hline $90-99$ & $1.0000(\mathrm{M} 7)$ & 3.61 & 0.165 & $\mathrm{~N} / \mathrm{A}$ \\
\hline $100-124$ & 0.6415 (M8) & 7.66 & 0.021 & $102 \mathrm{~T}, 0.998(* *)$ \\
\hline $125-210$ & $0.5975(\mathrm{M} 7)$ & 2.45 & 0.294 & $\mathrm{~N} / \mathrm{A}$ \\
\hline 211-234 & 0.4283 (M7) & 0.17 & 0.919 & N/A \\
\hline
\end{tabular}

Table S5. Analysis of rapidly evolving sites in the DUP240 family.

Sites under positive selection were identified using the codeML module in PAML. The DUP240 ortholog alignment (shown in fig. S11) was divided into segments according to results of DNA recombination breakpoint analysis using GARD. Model M7 (negative or neutral selection) and Model M8 (negative, neutral, or positive selection) were compared using the likelihood-ratio test, followed by the chi-squared significance test to determine where Model M8 should be accepted, which would indicate the presence of a signature of positive selection in the region. Segments 48-89 and 100-124 were identified as having such signatures. Bayes Empirical Bayes (BEB) analysis on these segments revealed sites under positive selection ( $\mathrm{dN} / \mathrm{dS}>1)$ with posterior probability $\operatorname{Pr}(\mathrm{dN} / \mathrm{dS}>1)$ greater than 0.95 . Codon positions are with respect to KTD1. 
bioRxiv preprint doi: https://doi.org/10.1101/2021.10.25.465803; this version posted October 25, 2021. The copyright holder for this preprint (which was not certified by peer review) is the author/funder. This article is a US Government work. It is not subject to copyright under 17 USC 105 and is also made available for use under a CCO license.

Tables included as separate files:

Table S6. Strains used in this study.

Table S7. Plasmids used in this study.

Table S8. Oligonucleotides used in this study. 